\title{
Architectural and Physiological Features to Gain High Yield in an Elite Rice Line YLY1
}

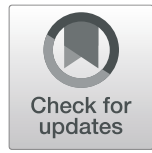

\author{
Shuoqi Chang ${ }^{1,2} \mathbb{B}$, Tiangen Chang ${ }^{2}$, Qingfeng Song ${ }^{1,2}$, Jun Wu ${ }^{1}$, Yi Luo ${ }^{1}$, Xiaolong Chen ${ }^{1}$, Xin-Guang Zhu ${ }^{2 *}$ and \\ Qiyun Deng ${ }^{1,3^{*}}$
}

\begin{abstract}
Identification of traits strongly associated with high yield can help future gene engineering towards improvements of productivity. Here we systematically determine the major architectural and physiological features associated with high yield in two elite historical hybrid rice cultivars, i.e., YLY1 and LYP9. Data from a six-year experiment show that high yield of YLY1 are related to a number of architectural and physiological parameters. Compared to LYP9, YLY1 had 5.5\% and $47.3 \%$ higher canopy photosynthesis under high and low photosynthetic photon flux densities, respectively, during the grain filling stage, an average $1.5 \%$ higher proportion of biomass allocation to aboveground tissues, a $4.5 \%-10.5 \%$ higher photosynthate reserve in leaf sheath before grain filling, and a more efficient photosynthate translocation during grain filling and finally an average $25.2 \%$ higher number of productive tillers. These features differ dramatically from features associated with high yield in YLY900 and Yongyou12", two other high-yielding rice cultivars in China. These identified features and their combinations can support designing new strategies in the future high-yield rice breeding.
\end{abstract}

Keywords: Super hybrid rice, YLY1, Photosynthesis, Grain filling, Ideotype

\section{Introduction}

Identification of architectural and physiological parameters associated with "ideotype", defined as ideal canopy structure, plays a crucial role in guiding high-yield breeding programs (Donald 1968; Yuan et al. 1994). It was reported that a national project was initiated to develop 'super' rice in 1996 in China, taking account of both improved yield and desirable adaptation to certain planting areas (Cheng et al. 1998; Cheng et al. 2007). One major goal of the 'super' rice project is to develop varieties capable of producing $100 \mathrm{~kg}$ grain day ${ }^{-1} \mathrm{ha}^{-1}$ (Yuan 2000). The 'super' hybrid rice breeding program was initiated in 1998 which combines the "ideotype" approach with intersubspecific heterosis (Yuan 2000). Major progress on

\footnotetext{
*Correspondence: zhuxg@sippe.ac.cn; dqy100@163.com

${ }^{2}$ National Key Laboratory of Plant Molecular Genetics, CAS Center of Excellence for Molecular Plant Sciences, Shanghai Institute of Plant

Physiology and Ecology, CAS, Shanghai 200032, China

'State Key Laboratory of Hybrid Rice, Hunan Hybrid Rice Research Center (HHRRC), Changsha 410125, China

Full list of author information is available at the end of the article
}

"ideotype" definition has been made through the 'super' hybrid rice breeding program. For example, Liang-youpei-jiu (LYP9), an elite rice cultivar, was released as the phase I super hybrid rice cultivar which has a yield potential of 10.5 grain/ha. After LYP9, several elite rice hybrid cultivars have been released for commercial production.

Y-Liang-you- $1^{\#}$ (YLY1) is a representative elite line during the second phase of the super hybrid rice, with a yield potential of $12 \mathrm{t} / \mathrm{ha}$, and has a largest planting area among five hybrid rice cultivars released from 2010 to 2016 (Fig. S1). YLY1 is a unique variety produced by two-line hybrid rice breeding method. It has been extensively planted in three rice planting area, i.e. the upper Yangze river, the area of middle and lower reaches of Yangze river and South China rice planting area in China (China Rice Data Center: http://www.ricedata.cn/variety/varis/604222.htm), suggesting that YLY1 not only has high yield potential, but also has a high yield stability, which is a feature required for any rice cultivar to be planted in different rice growing regions. YLY1 is an offspring of an elite TGMS
Springer Open

(c) The Author(s). 2020 Open Access This article is licensed under a Creative Commons Attribution 4.0 International License, which permits use, sharing, adaptation, distribution and reproduction in any medium or format, as long as you give appropriate credit to the original author(s) and the source, provide a link to the Creative Commons licence, and indicate if changes were made. The images or other third party material in this article are included in the article's Creative Commons licence, unless indicated otherwise in a credit line to the material. If material is not included in the article's Creative Commons licence and your intended use is not permitted by statutory regulation or exceeds the permitted use, you will need to obtain permission directly from the copyright holder. To view a copy of this licence, visit http://creativecommons.org/licenses/by/4.0/. 
(thermo-sensitive genic male sterile) line Y58S in China (Xia et al. 2011) crossed to male parent 9311 (Y58S/9311). YLY1 shows many desirable features regarded as "superior traits" by breeders. These traits include optimized canopy architecture, dark green leaves, erect flag leaf, narrow leaf, dwarf plants with a plant height of $108.2 \mathrm{~cm}$, panicle length of $24.7 \mathrm{~cm}, 181.2$ grains per panicle, grain filling rate of $80.9 \%$, thousand grain weight of $26.1 \mathrm{~g}$, and adaptability to a wide range of growing environments according to the data collected from $2013 \sim 2015$ by China Rice Data Center (http://www.ricedata.cn/variety/varis/604222.htm).

To achieve a high yield, a rice cultivar usually needs high source capacity, high sink capacity, and also wellcoordinated transport and allocation of resources among different source and sink organs (Chang and Zhu 2017). The source organs include not only leaves where photosynthesis occurs, but also root system where nutrient and water uptake takes place; sink organs include not only the panicle, but also different organs which consume photosynthate and nutrients for their growth and maintenance. The capacities of the source organs, sink organs or transport related organs are each determined by many different architectural and biochemical factors (Chang and Zhu 2017). Rice high yield formation usually requires delicate balance between different parameters and a superior value for a single parameter usually does not result in enhanced rice yield (Chang and Zhu 2017). Though rice yield potential has been improved substantially through breeding in the last few decades, the mechanisms underlying these yield enhancements are far from being elucidated. Understanding how these different elite rice cultivars achieved their high yields will offer new opportunities to combine these superior traits to develop cultivars with further improved productivity (Xue et al. 2015) (Li and Jiao 2002; Lv et al. 2017; Zou and Yao 2003; Zou 2003). In this study, we systematically evaluated the photosynthetic properties at leaf and canopy levels together with the characteristics at source, sink and flow organs in YLY1 and then compared them to those of LYP9, with a goal of identifying traits that contributed to high yield in YLY1. We also compared these identified traits with those in YLY900 and Yongyou $12^{\#}$, two other high-yielding rice cultivars in China (http://www.ricedata.cn/variety/varis/604222.htm). The analysis identified a number of superior traits of YLY1, which can be used to inform the future high-yield rice breeding programs.

\section{Results}

\section{Chlorophyll Content of Leaves of Various Positions at} Different Developmental Stages

Comparison with LYP9, chlorophyll contents of the 1st leaf and 3rd leaf in YLY1 were higher at tillering stage (TS), panicle differentiation stage (PDS), milk stage
(MS), and yellow ripe stage (YRS) (Table 1), and less difference of leaf chlorophyll contents for two cultivars was shown at MS. As for the 2nd leaf, chlorophyll contents of YLY1 were higher than LYP9 during most plant growth stages.

\section{The Net Photosynthesis $\left(P_{n}\right)$ of Leaves at Different Developmental Stages and the Responses of Leaf Photosynthetic Rates to Variation of Light Density and $\mathrm{CO}_{2}$ Concentration}

Little difference of $P_{n}(1.95 \%$, average) between YLY1 and LYP9 was observed at the TS, but the $P_{n}$ was higher in YLY1 from PDS to dough stage (DS) (Table 2), which were $6.56 \%-20.04 \%, 5.65 \%-16.39 \%$ higher than those of LYP9 at PDS and MS respectively (Table 2). The $A_{\text {sat }}$ observed in 2015 and 2016 was higher for YLY1 than that of LYP9 from TS to MS (Table 3).

At the MS, the mean $P_{n}$ of the uppermost three leaves in YLY1 was $32.90 \%$ higher than LYP9 (Fig. 1 A). More importantly, the mean $\mathrm{P}_{\mathrm{n}}$ of YLY1 in the basal three leaves (4th, 5th, and 6th leaves) was $127.55 \%$ higher than LYP9 (Fig. 1 A). At the DS, $P_{n}$ of the upper three leaves of YLY1 was 2.08\% higher than LYP9, while $P_{n}$ of YLY1 in the 4th leaf was 56.28\% higher than LYP9 (Fig. 1 B). Compared to LYP9, YLY1 maintained higher $P_{n}$ over LYP9 in the flag leaf, and also had higher $P_{n}$ in all other leaves during the MS and DS. Furthermore, the dark respiration of flag leaves in YLY1 were $8.11 \%$ lower than LYP9 at MS (Fig. S2).

Light response curves show that YLY1 had higher $\mathrm{P}_{\text {nmax }}$ than LYP9 (Fig. $2 \mathrm{~A}, \mathrm{~B}$ and Table 4). The $\mathrm{V}_{\text {cmax }}$ and $J_{\max }$ were $14.71 \%$ and $8.19 \%$ higher in YLY1 compared with LYP9 (Fig. 2 C, D, and Table 4).

Comparison of Canopy Leaf Area between LYP9 and YLY1 in the Growth Duration and Canopy Photosynthetic $\mathrm{CO}_{2}$ Uptake Rates at the Milk Stage

The leaf areas of the 1st, 2nd and 3rd leaves for YLY1 were less than that of LYP9 throughout the growth season (Table 5). In particular, at the MS, the leaf areas of YLY1 were $16.7 \%-22.7 \%$ and $21 \%-42 \%$ less than that of LYP9 in 2013 and 2015, respectively (Table 5). The canopy photosynthetic $\mathrm{CO}_{2}$ uptake rate of YLY1 was however higher than that of LYP9 (Fig. 3). The higher canopy $\mathrm{CO}_{2}$ assimilation of YLY1 is attributed to higher $\mathrm{P}_{\mathrm{n}}$ of the 2nd, 3rd and 4th leaves (Fig. $1 \mathrm{~A}, \mathrm{~B}$ ).

\section{The Number of Green Leaves in the Canopy}

The number of green leaves per hill in YLY1 were significantly less compared with LYP9 at the TS (Fig. 4); but from MS, YLY1 had higher number of green leaves per hill than LYP9, especially in 2014 (Fig. 4). 
Table 1 Chlorophyll Concentration (FW, $\mathrm{mg} \cdot \mathrm{g}^{-1}$ ) in canopy leaves with10 replicates were measured with SPAD-502(Minolta Camera Co. Ltd., Japan) at different growth stages, then use the SPAD vs actual chlorophyll content calibration for CV. YLY1 and LYP9 respectively in 2014 and 2015.TS means tillering stage, PDS means panicle differentiation stage, MS means Milk stage of grain filling, YRS means yellow ripe stage

\begin{tabular}{|c|c|c|c|c|c|c|c|c|c|}
\hline \multirow{2}{*}{$\begin{array}{l}\text { Leaf position } \\
\text { (Basipetal } \\
\text { leaf rank) }\end{array}$} & \multirow[t]{2}{*}{ Period } & \multicolumn{4}{|c|}{2014} & \multicolumn{4}{|c|}{2015} \\
\hline & & YLY1 (mean \pm SE) & LYP9 (mean \pm SE) & Difference & $P$ & YLY1 (mean \pm SE) & LYP9 (mean \pm SE) & Difference & $P$ \\
\hline \multirow[t]{5}{*}{ 1st leaf } & TS & $2.24 \pm 0.129$ & $1.75 \pm 0.021$ & $27.87 \%$ & $<0.01$ & / & / & / & $/$ \\
\hline & PDS & $1.92 \pm 0.025$ & $1.85 \pm 0.034$ & $4.01 \%$ & 0.116 & $1.94 \pm 0.043$ & $1.68 \pm 0.055$ & $15.57 \%$ & $<0.01$ \\
\hline & MS & $1.99 \pm 0.0029$ & $1.89 \pm 0.0033$ & $4.88 \%$ & $<0.01$ & $1.93 \pm 0.086$ & $1.86 \pm 0.013$ & $3.67 \%$ & $<0.01$ \\
\hline & YRS & $1.64 \pm 0.0077$ & $1.023 \pm 0.076$ & $60.50 \%$ & $<0.01$ & $1.82 \pm 0.026$ & $1.81 \pm 0.027$ & $0.42 \%$ & 0.842 \\
\hline & TS & $1.98 \pm 0.0063$ & $1.84 \pm 0.0089$ & $7.65 \%$ & $<0.01$ & / & / & / & / \\
\hline \multirow[t]{4}{*}{ 2nd leaf } & PDS & $1.97 \pm 0.0055$ & $1.86 \pm 0.0056$ & $5.77 \%$ & $<0.01$ & $1.97 \pm 0.0065$ & $1.84 \pm 0.0083$ & $7.25 \%$ & $<0.01$ \\
\hline & MS & $1.97 \pm 0.0345$ & $1.95 \pm 0.019$ & $1.03 \%$ & 0.345 & $1.95 \pm 0.015$ & $1.86 \pm 0.013$ & $4.69 \%$ & $<0.01$ \\
\hline & YRS & $1.67 \pm 0.0508$ & $1.01 \pm 0.0379$ & $64.41 \%$ & $<0.01$ & $1.95 \pm 0.161$ & $1.86 \pm 0.028$ & $0.76 \%$ & 0.939 \\
\hline & TS & $1.99 \pm 0.0054$ & $1.81 \pm 0.0277$ & $10.02 \%$ & $<0.01$ & / & / & / & / \\
\hline \multirow[t]{3}{*}{$3 r d$ leaf } & PDS & $1.98 \pm 0.0041$ & $1.86 \pm 0.0058$ & $6.81 \%$ & $<0.01$ & $1.96 \pm 0.0049$ & $1.79 \pm 0.0042$ & $9.32 \%$ & $<0.01$ \\
\hline & MS & $1.93 \pm 0.0317$ & $1.89 \pm 0.0229$ & $2.54 \%$ & 0.267 & $1.91 \pm 0.0034$ & $1.74 \pm 0.0071$ & $9.90 \%$ & $<0.01$ \\
\hline & YRS & / & / & / & / & $1.77 \pm 0.0057$ & $1.47 \pm 0.0068$ & $20.51 \%$ & $<0.01$ \\
\hline
\end{tabular}

Biomass and the stem's Diameter, Length of the LodgingResistant Traits

LYP9 showed higher biomass than YLY1 at TS (Fig. 5). However, the biomass of YLY1 increased gradually, especially during the grain filling stage (Fig. 5). At the YRS stage, YLY1 exhibited higher biomass than LYP9 (Fig. 5). Compared to those in LYP9, the 2nd and 3rd internodes, counted from the base of the stem, of YLY1 were longer, but not the 5th internode, which is in line with the panicle of YLY1 was significantly shorter than that of LYP9 (Fig. 6 A). The diameter of the basal internode, i.e. the first and

Table 2 The net photosynthesis rate $\left(P_{n}\right)$ of uppermost or flag leaves with a portable photosynthesis system LI-6400XT, the photosynthetic photon flux density (PPFD) were $1000 \mu \mathrm{mol} \mathrm{m} \mathrm{m}^{-2} \mathrm{~s}^{-1}$ at different growth stages for $\mathrm{cV}$. YLY1 and LYP9. The $p$ values are probability of two-tail t-test. $n=10, P_{n}\left(\mu m o l m^{-2} s^{-1}\right.$ ) (mean $\left.\pm S D\right)$. TS means tillering stage, PDS means panicle differentiation stage, HFS means heading and flowering stage, MS means milk stage of grain filling, DS means dough stage of grain filling

\begin{tabular}{|c|c|c|c|c|c|c|}
\hline Year & & TS & PDS & HFS & MS & DS \\
\hline \multirow[t]{4}{*}{2011} & YLY1 & I & 1 & $23.84 \pm 1.16$ & $20.00 \pm 1.07$ & $14.77 \pm 2.05$ \\
\hline & LYP9 & / & / & $20.98 \pm 1.06$ & $20.09 \pm 1.40$ & $14.98 \pm 2.09$ \\
\hline & Difference & / & / & $13.63 \%$ & $-0.45 \%$ & $-1.40 \%$ \\
\hline & $p$ & / & / & $<0.01$ & 0.819 & 0.757 \\
\hline \multirow[t]{4}{*}{2012} & YLY1 & $23.24 \pm 0.59$ & $25.58 \pm 1.36$ & $20.22 \pm 0.15$ & $20.10 \pm 1.21$ & $15.75 \pm 1.11$ \\
\hline & LYP9 & $24.05 \pm 0.48$ & $21.31 \pm 1.47$ & $18.16 \pm 1.66$ & $17.27 \pm 0.03$ & $14.27 \pm 1.16$ \\
\hline & Difference & $-3.37 \%$ & $20.04 \%$ & $11.34 \%$ & $16.39 \%$ & $10.37 \%$ \\
\hline & $p$ & $<0.01$ & $<0.01$ & $<0.01$ & $<0.01$ & $<0.01$ \\
\hline \multirow[t]{4}{*}{2013} & YLY1 & $26.70 \pm 0.53$ & $25.08 \pm 0.19$ & $23.88 \pm 0.25$ & $21.39 \pm 0.19$ & $16.95 \pm 0.24$ \\
\hline & LYP9 & $25.00 \pm 0.49$ & $22.61 \pm 0.33$ & $23.79 \pm 0.26$ & $20.15 \pm 0.18$ & $16.49 \pm 0.30$ \\
\hline & Difference & $6.80 \%$ & $10.90 \%$ & $0.41 \%$ & $6.13 \%$ & $2.81 \%$ \\
\hline & $p$ & $<0.01$ & $<0.01$ & 0.7967 & $<0.01$ & 0.2472 \\
\hline \multirow[t]{4}{*}{2014} & YLY1 & $28.43 \pm 0.51$ & $26.98 \pm 0.35$ & $25.04 \pm 0.73$ & $21.51 \pm 0.37$ & $17.71 \pm 0.87$ \\
\hline & LYP9 & $27.75 \pm 0.38$ & $25.32 \pm 0.65$ & $24.77 \pm 0.81$ & $20.36 \pm 0.55$ & $15.98 \pm 0.47$ \\
\hline & Difference & $2.43 \%$ & $6.56 \%$ & $1.09 \%$ & $5.65 \%$ & $10.84 \%$ \\
\hline & $p$ & $<0.05$ & $<0.01$ & 0.6608 & $<0.05$ & $<0.05$ \\
\hline
\end{tabular}


Table 3 Maximum light saturated rate of leaf photosynthesis $\left(A_{\text {sat }}\right)$ of uppermost or flag leaves were measured with a portable photosynthesis system LI-6400XT, and the photosynthetic photon flux density (PPFD) were $1600 \mu \mathrm{mol} \mathrm{m}^{-2} \mathrm{~s}^{-1}$ at different growth stages for $\mathrm{CV}$. YLY1 and LYP9. The $p$ values are probability of two-sided t-test. $n=10 . A_{\text {sat }}\left(\mu \mathrm{mol} \mathrm{m}^{-2} \mathrm{~s}^{-1}\right)(\mathrm{mean} \pm \mathrm{SD})$

\begin{tabular}{|c|c|c|c|c|c|c|}
\hline Year & & TS & EPDS & LPDS & MS & DS \\
\hline \multirow[t]{4}{*}{2015} & YLY1 & $34.17 \pm 0.79$ & I & $26.88 \pm 1.33$ & $25.18 \pm 0.44$ & $13.30 \pm 0.48$ \\
\hline & LYP9 & $31.0 \pm 0.84$ & / & $25.30 \pm 0.78$ & $24.19 \pm 0.59$ & $12.78 \pm 0.75$ \\
\hline & Difference & $10.23 \%$ & / & $6.25 \%$ & $4.15 \%$ & $4.07 \%$ \\
\hline & $p$ & $<0.01$ & / & $<0.01$ & $<0.05$ & 0.3582 \\
\hline \multirow[t]{4}{*}{2016} & YLY1 & / & $33.01 \pm 0.91$ & $31.53 \pm 0.90$ & / & $15.87 \pm 0.47$ \\
\hline & LYP9 & / & $28.78 \pm 0.49$ & $29.17 \pm 0.46$ & / & $15.64 \pm 1.00$ \\
\hline & Difference & / & $14.70 \%$ & $8.09 \%$ & / & $1.47 \%$ \\
\hline & $p$ & / & $<0.01$ & $<0.05$ & / & 0.6542 \\
\hline
\end{tabular}

second internodes, and the uppermost internode, i.e. the 5 th internode, in LYP9 were higher than those of YLY1 (Fig. 6 B).

\section{The Allocation of Photosynthate among Different Organs}

YLY1 had a lower ratio of the below-ground biomass to the above-ground to total biomass than LYP9 at the YRS (Fig. S3). At the TS, YLY1 showed a higher proportion of biomass in leaves (Fig. 7); however, YLY1 showed lower proportion of biomass partitioned into leaf from PDS to YRS (Fig. 7). Compared to LYP9, YLY1 had higher proportion of biomass partitioned into sheath at the PDS, while it had a lower proportion of biomass partitioned into sheath at the MS and YRS (Fig. 7). At the MS, LYP9 showed higher proportion of biomass partitioned into stem though at YRS, the proportion of biomass partitioned into stem was similar between these two cultivars (Fig. 7). YLY1 had higher ratio of the panicle biomass to total biomass from the MS to YRS (Fig. 7). The photosynthate was transported to the grains at the grain filling stage, the superior, middle and inferior grains in YLY1 were all heavier than LYP9 (Fig. 8), and the grain filling rate of YLY1 was faster than that of LYP9 after anthesis (Fig. 9). YLY1 had higher harvest index at the harvest stage (Fig. $10 \mathrm{~A}$ ).

\section{Comparison of the Final Grain Yield and Yield Components between YLY1 and LYP9}

Among the four yield components, i.e., effective panicle number, number of grains per panicle, seed setting rate, and 1000-grain weight, YLY1 had more effective panicle number per hill (Fig. 10 B, Table 6). Furthermore, the seed setting rate and 1000-grain weigh were also higher in YLY1 compared to LYP9 (Table 6). The grain length of YLY1 was longer than LYP9, and the width of grain was similar to LYP9 (Table 7). Compared to LYP9,
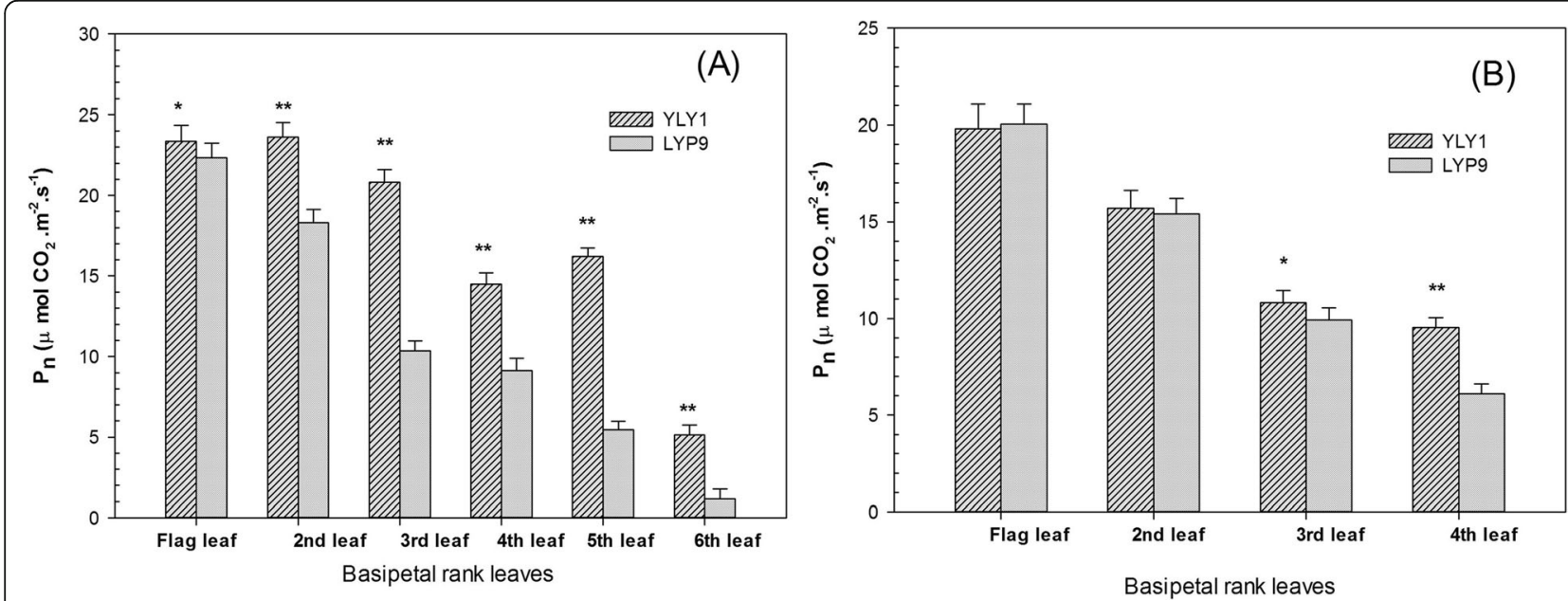

Fig. 1 Net photosynthesis rates of different leaves for CV. YLY1 and LYP9 at the milk (a) and dough (b) stages in 2011. The bar is the standard deviation of 5 replicates. " $*$ ", "***" means significance level at $p=0.05$ or $p=0.01$, respectively 

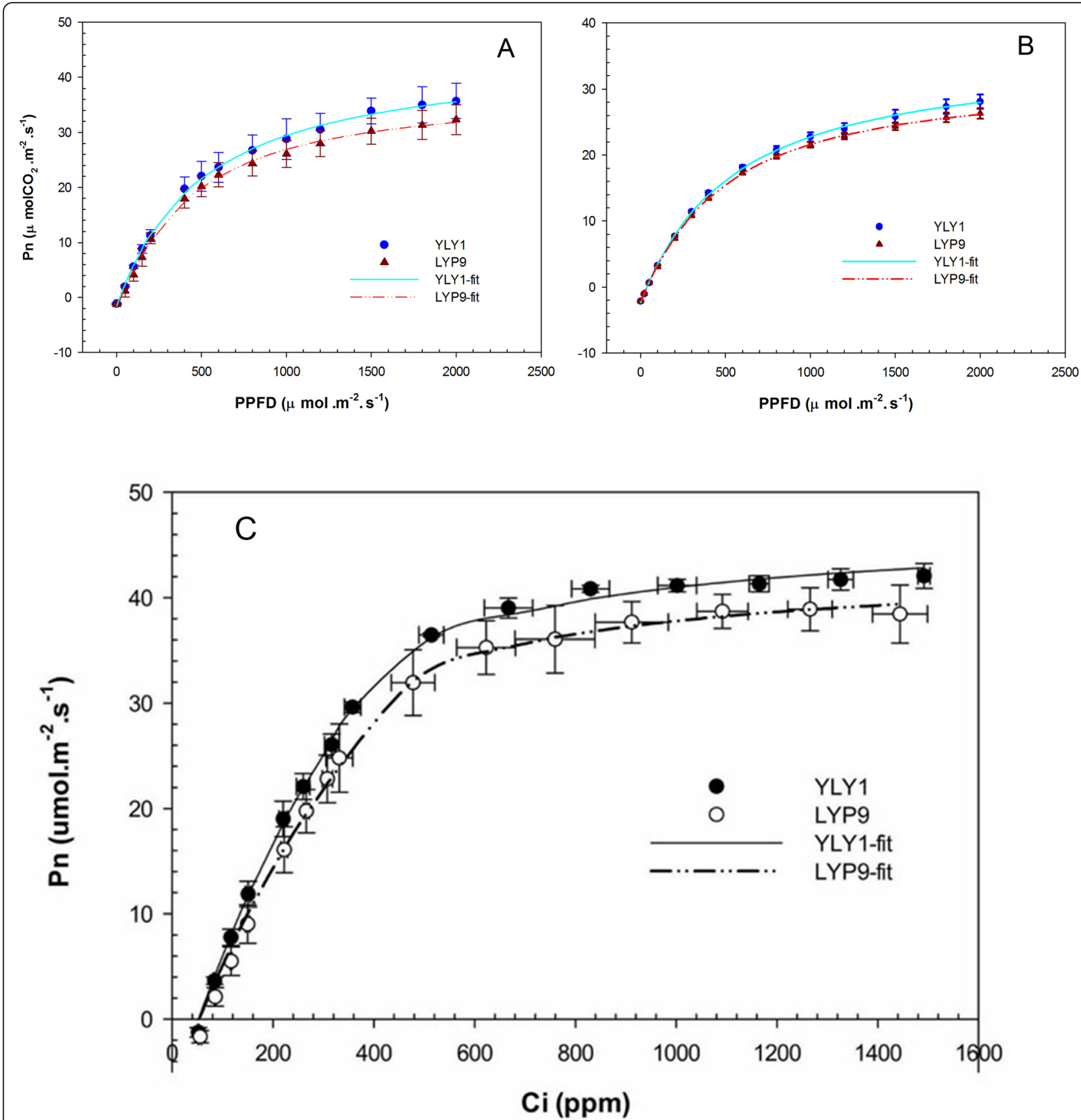

Fig. 2 The photosynthetic $\mathrm{CO}_{2}$ uptake rates $\left(\mathrm{P}_{\mathrm{n}}\right)$ under different photosynthetic photon flux densities in flag leaves at different developmental stages. a Early milk stage, $\mathbf{b}$ Late milk stage. The $\mathrm{CO}_{2}$ concentrations used during the measurements were $380-400$ ppm and 385 ppm for early milk stage and late milk stage respectively. The photosynthetic $\mathrm{CO}_{2}$ uptake rates under different intercellular $\mathrm{CO}_{2}$ concentration in flag leaves for YLY1 (c) and LYP9 (d) measured at the milk stage. During the measurements, the PPFD used was $1600 \mathrm{\mu molm}^{-2} \mathrm{~s}^{-1}$. The bar is the standard deviations of 3 replicates

YLY1 had higher plant height and panicle length, less grain number per panicle and longer panicle length resulting in lower grain density of panicle (Table 6, Fig. $10 \mathrm{C}$ ). The grain yield of YLY1 was $9.82-12.03 \mathrm{t} / \mathrm{ha}$, significantly higher than the grain yield of LYP9 (9.09$11.89 \mathrm{t} / \mathrm{ha}$ ) (Table 8).

\section{Discussion}

Systematic examination of the physiological, architectural and agronomic traits in elite rice cultivars provides a way to elucidate the potential mechanisms responsible for their high yield potential, which can be used in the future rice breeding programs. In this 
Table 4 Parameters derived from the light response curves of $\mathrm{CO}_{2}$ fixation, the maximal $\mathrm{Pn}$ at light saturation point (Pnmax), apparent quantum yield (AQY) and dark respiration rate (Rd). The ambient $\mathrm{CO}_{2}$ concentration during measurements was 380-400 ppm in EMS (Early milk stage) (A) and 385 ppm in LMS (late milk stage) (B). Maximum rates of carboxylation at both $\mathrm{CO}_{2}$ and RuBP saturation (Vcmax) and maximum rate of electron transport (Jmax) derived from the $\mathrm{CO}_{2}$ response curves of photosynthetic $\mathrm{CO}_{2}$ uptake rate measured in 2013. $n=3$

\begin{tabular}{|c|c|c|c|c|c|c|}
\hline & \multicolumn{2}{|c|}{$P_{n \max }\left(\mu \mathrm{mol} \mathrm{m} \mathrm{m}^{-2} \mathrm{~s}^{-1}\right)$} & \multicolumn{2}{|l|}{ AQY } & \multirow[t]{2}{*}{$V_{c \max }\left(\mu \mathrm{mol} \mathrm{m} \mathrm{m}^{-2} \mathrm{~s}^{-1}\right)$} & \multirow[t]{2}{*}{$J_{\max }\left(\mu \mathrm{mol} \mathrm{m}^{-2} \mathrm{~s}^{-1}\right)$} \\
\hline & $A$ & $B$ & A & $B$ & & \\
\hline YLY1 & $46.03 \pm 3.14$ & $37.28 \pm 3.88$ & $0.09 \pm 0.01$ & $0.07 \pm 0.004$ & $105.91 \pm 4.35$ & $191.66 \pm 1.99$ \\
\hline LYP9 & $39.72 \pm 7.79$ & $34.49 \pm 2.81$ & $0.08 \pm 0.02$ & $0.06 \pm 0.005$ & $92.33 \pm 7.32$ & $177.15 \pm 7.19$ \\
\hline P & 0.17 & 0.325 & $<0.05$ & 0.33 & $<0.05$ & $<0.05$ \\
\hline Difference & $15.89 \%$ & $8.11 \%$ & $12.99 \%$ & $4.42 \%$ & $14.71 \%$ & $8.19 \%$ \\
\hline
\end{tabular}

study, we systematically evaluated the features associated with source, sink and photosynthate translocation related parameters in YLY1, an elite hybrid rice cultivar with high yields and having the largest planting areas in China between 2010 and 2016 (Huang et al. 2012). We also compared these features of this line with an earlier super rice cultivar, LYP9 (Zou 2003) and Yongyou12\# (Wei et al. 2016). Herein, we first discuss the features that contribute to high yield and wide planting area in YLY1. Then we discuss the major differences in the mechanisms underlying high yields between YLY1 and other two rice cultivars, i.e.YLY900 and Yongyou12\#. Finally, we specifically discuss new targets which can be explored in the future high-yield rice breeding programs.

\section{Factors Contributed to the High Yield and Wide Planting Area in YLY1}

Though photosynthesis is a key determinant for enhanced yield, an effective attempt for improved photosynthesis in hybrid rice breeding programs is less made so far yet. Here we show that, as compared to LYP9, YLY1 indeed exhibits improved photosynthetic efficiency compared to LYP9 under both high light and also under low light conditions (Fig. 3). Using canopy photosynthesis and transpiration system, we found that the YLY1 had much higher total canopy photosynthetic $\mathrm{CO}_{2}$ uptake rates during the grain filling stage (Fig. 3). The increase in canopy photosynthesis can be attributed to a number of factors. First, the YLY1 had higher $P_{n}$ than LYP9 in most growth stages, in particular at the PDS and MS (Table 2); secondly, YLY1 has a desirable canopy architecture which benefits canopy photosynthesis, e.g. YLY1 has less leaf areas at the top canopy layer, and had smaller leaf angles for the upper three leaves (Li 2013), which ensures sufficient light to penetrate into deeper canopy. Furthermore, YLY1 possesses more green leaves, which are photosynthetically competent, at lower layers of a canopy at later developmental stages. This might be due to the increased light

Table 5 The leaf areas of canopy eaves of main stems were measured with a handheld laser leaf area meter (Ci-203, CID, Inc., Vancouver, WA, USA) at different growth stages for cV. YLY1 and LYP9 in 2013, 2014 and 2015.n- = 10

\begin{tabular}{|c|c|c|c|c|c|c|c|c|c|c|c|c|c|}
\hline \multicolumn{14}{|c|}{ Leaf area $\left(\mathrm{cm}^{2}\right)$} \\
\hline \multirow[t]{2}{*}{ Period } & \multirow{2}{*}{$\begin{array}{l}\text { Leaf position } \\
\text { (Basipetal } \\
\text { leaf rank) }\end{array}$} & \multicolumn{2}{|l|}{2013} & \multirow[t]{2}{*}{ Difference } & \multirow[t]{2}{*}{$p$} & \multicolumn{2}{|l|}{2014} & \multirow[t]{2}{*}{ Difference } & \multirow[t]{2}{*}{$p$} & \multicolumn{2}{|l|}{2015} & \multirow[t]{2}{*}{ Difference } & \multirow[t]{2}{*}{$p$} \\
\hline & & $\begin{array}{l}\text { YLY1 } \\
(\text { mean } \pm \text { SE) }\end{array}$ & $\begin{array}{l}\text { LYP9 } \\
\text { (mean } \pm \text { SE) }\end{array}$ & & & $\begin{array}{l}\text { YLY1 } \\
\text { (mean } \pm \text { SE) }\end{array}$ & $\begin{array}{l}\text { LYP9 } \\
(\text { mean } \pm \text { SE) }\end{array}$ & & & $\begin{array}{l}\text { YLY1 } \\
(\text { mean } \pm \text { SE) }\end{array}$ & $\begin{array}{l}\text { LYP9 } \\
(\text { mean } \pm \text { SE) }\end{array}$ & & \\
\hline \multirow[t]{3}{*}{ TS } & 1st leaf & $32.47 \pm 0.83$ & $45.19 \pm 0.19$ & $-39.18 \%$ & $<0.01$ & $62.72 \pm 0.93$ & $60.44 \pm 2.15$ & $3.76 \%$ & 0.3688 & I & 1 & 1 & 1 \\
\hline & 2nd leaf & $42.67 \pm 2.48$ & $40.75 \pm 1.41$ & $4.72 \%$ & 0.3074 & $41.36 \pm 0.78$ & $41.02 \pm 1.73$ & $0.82 \%$ & 0.8531 & / & / & / & / \\
\hline & 3rd leaf & $44.91 \pm 1.42$ & $47.90 \pm 0.82$ & $-6.25 \%$ & $<0.05$ & $27.09 \pm 0.78$ & $29.43 \pm 1.73$ & $-7.96 \%$ & 0.5143 & / & / & / & / \\
\hline \multirow[t]{3}{*}{ PDS } & 1st leaf & $34.80 \pm 0.81$ & $45.37 \pm 0.73$ & $-30.36 \%$ & $<0.01$ & $71.87 \pm 1.57$ & $84.60 \pm 0.95$ & $-17.71 \%$ & $<0.01$ & $63.28 \pm 2.59$ & $48.24 \pm 4.71$ & $31 \%$ & $<0.05$ \\
\hline & 2nd leaf & $49.19 \pm 1.48$ & $59.76 \pm 1.10$ & $-21.49 \%$ & $<0.01$ & $87.26 \pm 2.07$ & $96.15 \pm 1.56$ & $-9.25 \%$ & $<0.01$ & $72.40 \pm 1.14$ & $80.32 \pm 3.00$ & $-10 \%$ & $<0.05$ \\
\hline & 3rd leaf & $47.86 \pm 0.52$ & $55.95 \pm 1.17$ & $-16.90 \%$ & $<0.01$ & $82.67 \pm 3.69$ & $78.15 \pm 1.39$ & $5.79 \%$ & 0.2948 & $68.02 \pm 2.33$ & $82.27 \pm 2.19$ & $-17 \%$ & $<0.01$ \\
\hline \multirow[t]{3}{*}{ MS } & 1st leaf & $35.98 \pm 0.88$ & $41.99 \pm 0.72$ & $-16.68 \%$ & $<0.01$ & $71.25 \pm 4.05$ & $72.37 \pm 3.18$ & $-1.58 \%$ & 0.8376 & $51.98 \pm 3.72$ & $88.97 \pm 2.06$ & $-42 \%$ & $<0.01$ \\
\hline & 2nd leaf & $47.65 \pm 0.63$ & $61.65 \pm 0.94$ & $-22.71 \%$ & $<0.01$ & $89.70 \pm 3.14$ & $89.24 \pm 2.88$ & $0.52 \%$ & 0.9192 & $49.55 \pm 1.19$ & $72.18 \pm 2.31$ & $-31 \%$ & $<0.01$ \\
\hline & 3rd leaf & $52.93 \pm 0.69$ & $66.81 \pm 0.98$ & $-20.78 \%$ & $<0.01$ & $90.10 \pm 1.38$ & $94.85 \pm 1.02$ & $-5.01 \%$ & $<0.05$ & $76.09 \pm 3.39$ & $59.83 \pm 1.51$ & $-21 \%$ & $<0.01$ \\
\hline \multirow[t]{3}{*}{ YRS } & 1st leaf & $31.82 \pm 1.45$ & $27.67 \pm 0.56$ & $15.00 \%$ & $<0.01$ & $48.49 \pm 1.12$ & $43.17 \pm 0.82$ & $12.31 \%$ & $<0.01$ & $59.21 \pm 4.89$ & $90.81 \pm 3.66$ & $-35 \%$ & $<0.01$ \\
\hline & 2nd leaf & $45.42 \pm 1.24$ & $46.41 \pm 0.63$ & $-2.14 \%$ & 0.3478 & $54.80 \pm 0.68$ & $51.96 \pm 1.36$ & $-5.18 \%$ & $<0.05$ & $55.89 \pm 1.34$ & $76.08 \pm 3.86$ & $-27 \%$ & $<0.01$ \\
\hline & 3rd leaf & $37.21 \pm 0.73$ & $31.84 \pm 1.82$ & $16.88 \%$ & $<0.01$ & $49.17 \pm 1.77$ & $29.85 \pm 0.79$ & $-39.29 \%$ & $<0.01$ & $57.69 \pm 1.41$ & $79.99 \pm 3.18$ & $-28 \%$ & $<0.01$ \\
\hline
\end{tabular}




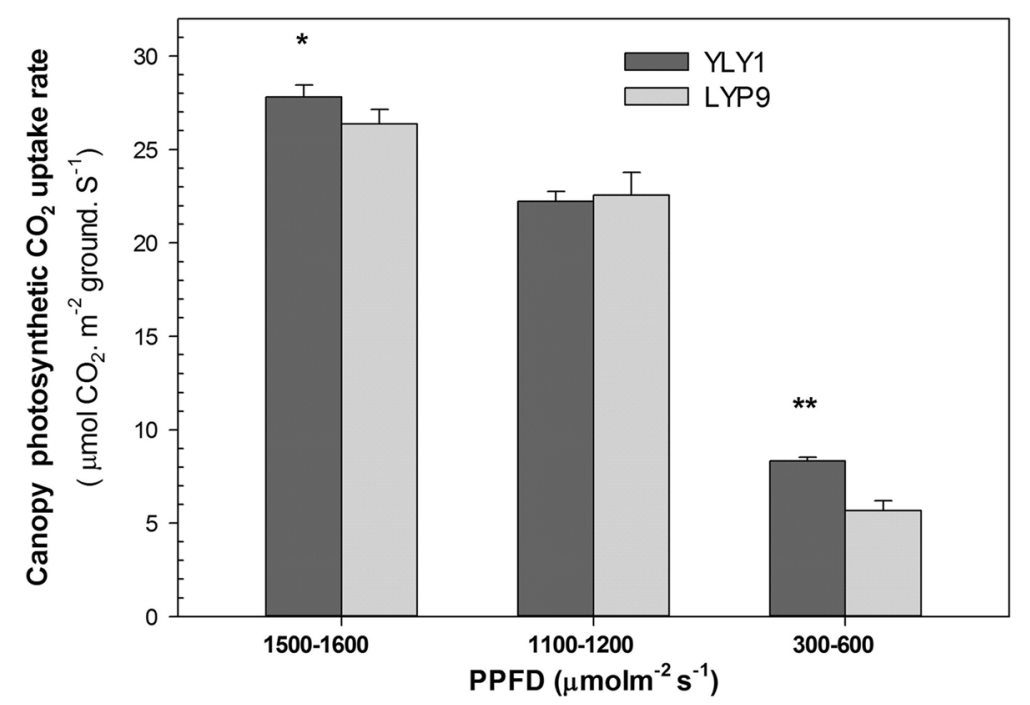

Fig. 3 Canopy photosynthesis measured using the canopy photosynthesis and transpiration system (Song et al. 2016) at the grain filling stage in 2015. The photosynthetic photon flux density (PPFD) represents the PPFD above the CAPTS. "*," " "**" represent significance levels of $p=0.05$ and $p=0.01$ levels, respectively. The bar represents the standard deviation of 4 replicates

availability for the lower-layer leaves, as a result of the smaller leaf angle and decreased leaf area in top layers (Ling et al. 1982) (Table. 5). This higher photosynthetic capacity in YLY1 can provide sufficient photosynthate required to support rapid grain filling (Fig. 9). Indeed, in YLY9, the grain filling rates of the superior, middle and inferior grains were all greater than LYP9 (Fig. 9).

The less leaf area in the uppermost three leaves observed in YLY1 may also allow adequate air flow inside the canopy, which can decrease relative humidity in the canopy and hence decrease the vulnerability of rice plants to pathogen or fungus derived disease. Compared with LYP9, YLY1 exhibits higher leaf chlorophyll content. Considering the typical linear relationship between leaf chlorophyll content with nitrogen content and $\mathrm{Ru}$ bisco (Evans 1989), YLY1 should have a higher leaf nitrogen content and Rubisco content. The high leaf chlorophyll content in YLY1 underlies the high demand for nitrogen fertilizer, especially at the later developmental stages. It is worth mentioning here that many theoretical and experimental evidences suggest that higher leaf chlorophyll content might be counterproductive for canopy photosynthetic $\mathrm{CO}_{2}$ uptake rates (Ort et al. 2011; Song et al. 2017). Therefore, though maintaining
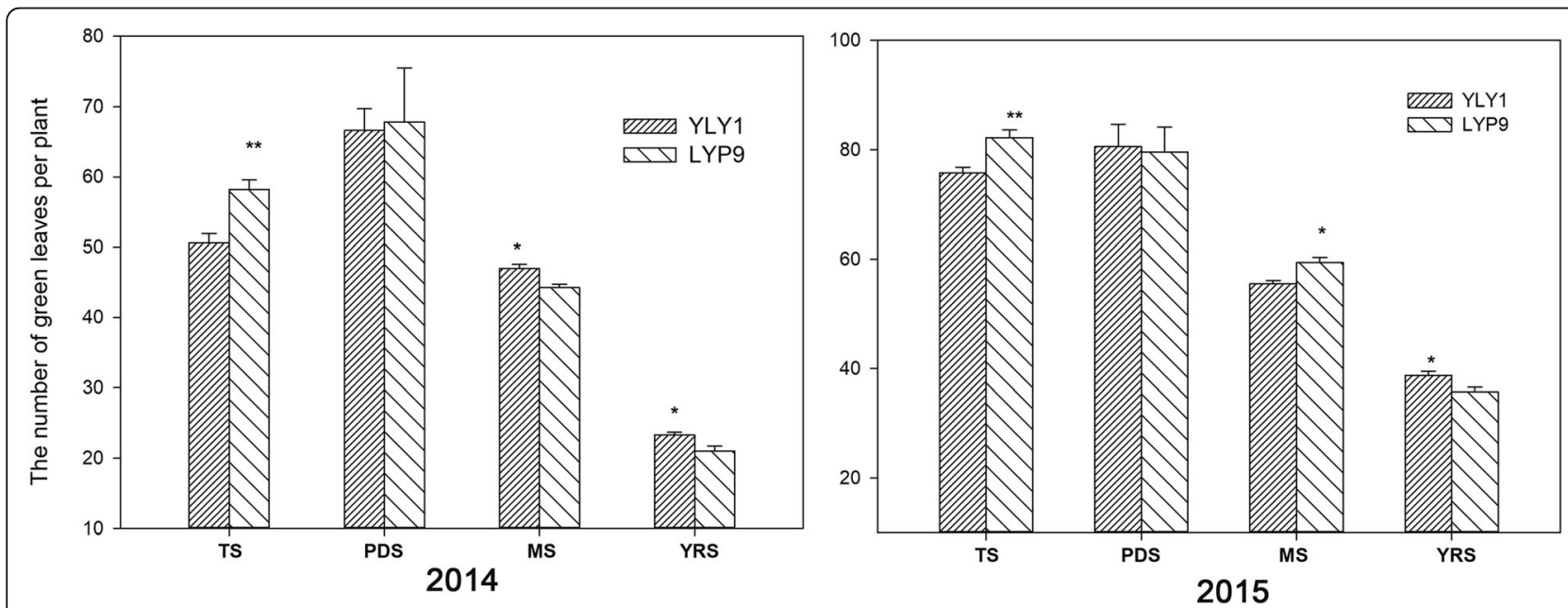

Fig. 4 The number of green leaves per hill during the growth season in 2014 and 2015. TS: tillering stage; PDS: panicle differentiation stage; MS: milk stage of grain filling; YRS: yellow ripe stage, "**" "***" represent significance levels of $p=0.05$ and $p=0.01$ levels, respectively. The bar represents the standard deviation of 10 replicates 


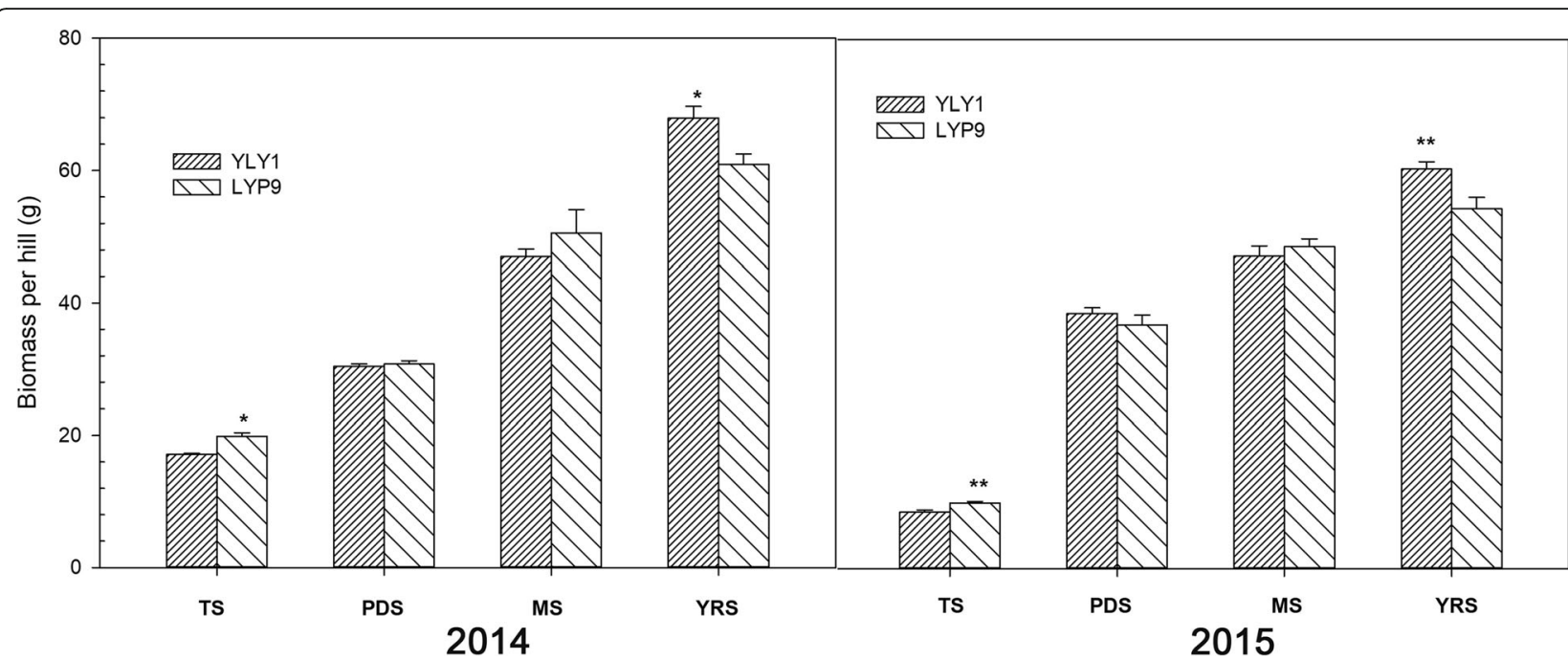

Fig. 5 The above ground biomass dry weights for both YLY1 and LYP9 at different developmental stages during the growth seasons in 2014 and 2015. See definitions of different stages in Fig. 4. "**," "**" represent significance levels of $p=0.05$ and $p=0.01$ levels, respectively. The bar represents the standard deviation of 10 replicate

large functional leaf area to improves canopy photosynthesis, however, the leaf chlorophyll content might be further optimized to gain further increase in canopy photosynthesis.

The second feature that is associated with high yield of YLY1 is that much less biomass was allocated to underground compared to LYP9 at YRS (Fig. S3). Theoretically, having higher proportion of biomass partitioned into above-ground leaf and stem as compared to underground root can lead to increase in both leaf area and stem biomass, which in turn can contribute to higher photosynthate production (Chang and Zhu 2017). Considering that YLY1 had a higher biomass accumulation at the end of the growing season (Fig. 5) and it also has a relatively higher leaf chlorophyll concentration (Table 1) and photosynthetic rates (Fig. 1; Table 2) during most of the growing season, YLY1 may have a higher total nitrogen content for the aboveground biomass. Further considering the relatively lower ratio of underground to aboveground biomass (Wang 2011; Yi 2016), the higher nitrogen contents in YLY1 in aboveground biomass implies that YLY1 may have a higher root nutrient uptake capacity than LYP9. More experiments are needed to confirm this hypothesis. Leaves that usually contribute photosynthate to support root growth and function, e.g. the 4th, 5th and 6th leaves (Ling et al. 1982), showed much higher photosynthetic activity in YLY1 as compared to LYP9 (Fig. 1), which might provide more carbohydrate to support the nitrogen uptake capacity of the root system. Therefore, both the decreased root to shoot ratio and also increased nitrogen uptake capacity in YLY1 may contribute to its high yield.
Thirdly, YLY1 showed a high sheath reserve storage and mobilization capacity. Increased sheath biomass was observed in YLY1 compared to that in LYP9 at the PDS (Fig. 7); in contrast, at YRS (Fig. 7), YLY1 showed decreased sheath biomass compared to LYP9. The high photosynthate reserve in YLY1 in the sheath at PDS is consistent with its higher photosynthetic capacity than LYP9 (Tables 2 and 3). This increased reserve might have contributed to the faster and better initiation of grain filling process, leading to better grain filling for both the superior grains and the inferior grains (Fig. 9). In addition, YLY1 had more efficient photosynthate translocation from sheath to grain during MS and DS (Fig. 7), which might have contributed to the much higher harvest index of YLY1 compared to LYP9 (Fig. $10 \mathrm{~A}$ ).

Fourthly, compared to LYP9, YLY1 had more productive tillers, compared to LYP9, which results in more effective panicles number per hill (Table 6, Fig. 10B). The higher number of productive tillers are attributed to both the increased canopy photosynthetic capacity at the grain filling stages and the ability of lower layer leaves maintaining photosynthetic capacity, which could provide sufficient photosynthate to support a robust and functional root system.

In summary, YLY1 represents an excellent example of achieving high yield through high source capacity, high sink capacity and efficient transportation between storage tissue and panicle. The high source capacity of YLY1, as reflected by its high canopy photosynthetic rate, can be attributed to a higher leaf photosynthesis rate, a superior canopy architecture ensuring better light 

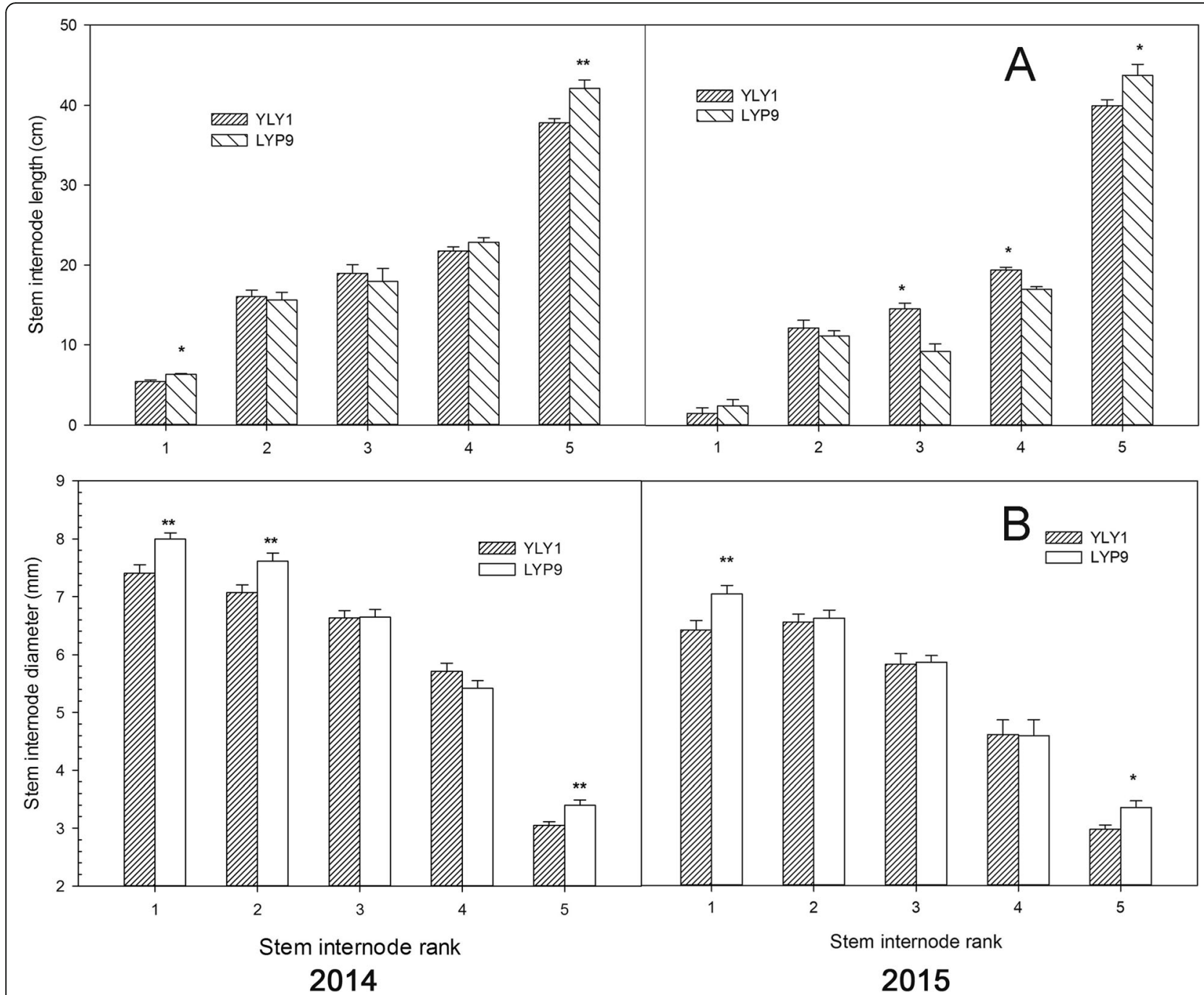

Fig. 6 The length and diameter of stem internode for YLY1 and LYP9 at the Yellow ripe stage in 2014 and 2015. "*," "**" represent significance levels of $p=0.05$ and $p=0.01$ levels, respectively. The bar represents the standard deviation of 5 replicates

penetration, and longer functional duration of leaves. Maintaining a low root:shoot ratio and a high nitrogen uptake capacity per root mass also contribute to high yield of YLY1 as well. The large number of productive tillers and high harvest index of YLY1 ensure sufficient sink capacity to alleviate potential feedback inhibition of photosynthetic activity. YLY1 also has a higher stem and sheath nonstructural carbohydrate storage before grain filling and high capacity of translocating the stored carbohydrate into grain during the grain filling period.

\section{Comparison of YLY1 with Other Major Elite High Yielding Varieties}

Different elite rice lines can achieve high yield through different mechanisms (Chang et al. 2019, Field Crop Research). Here we describe the major morphological and physiological features in two other elite rice cultivars, i.e.
YLY900 and Yongyou12\#, and then discuss the major differences between mechanisms used by YLY1 and these two cultivars to achieve high yield.

YLY900 is a rice cultivar which reached a record-high rice yield of 14.8 tons per acre in 2013(Chang et al. 2016). YLY 900 has a large leaf area for the uppermost three leaves, has appropriate lengths of internodes featured by shorter internode length for the basal internodes and a longer panicle-linked internode. Furthermore, leaves of YLY900 maintain a longer functional duration. YLY900 maintains a large number of green leaves, stores a large amount of carbohydrate in stems and sheaths before the grain filling stage, and has a high capacity of remobilizing resources to support grain filling. YLY900 requires a large input of nitrogen fertilizers at the grain filling stage to gain its high yield. 

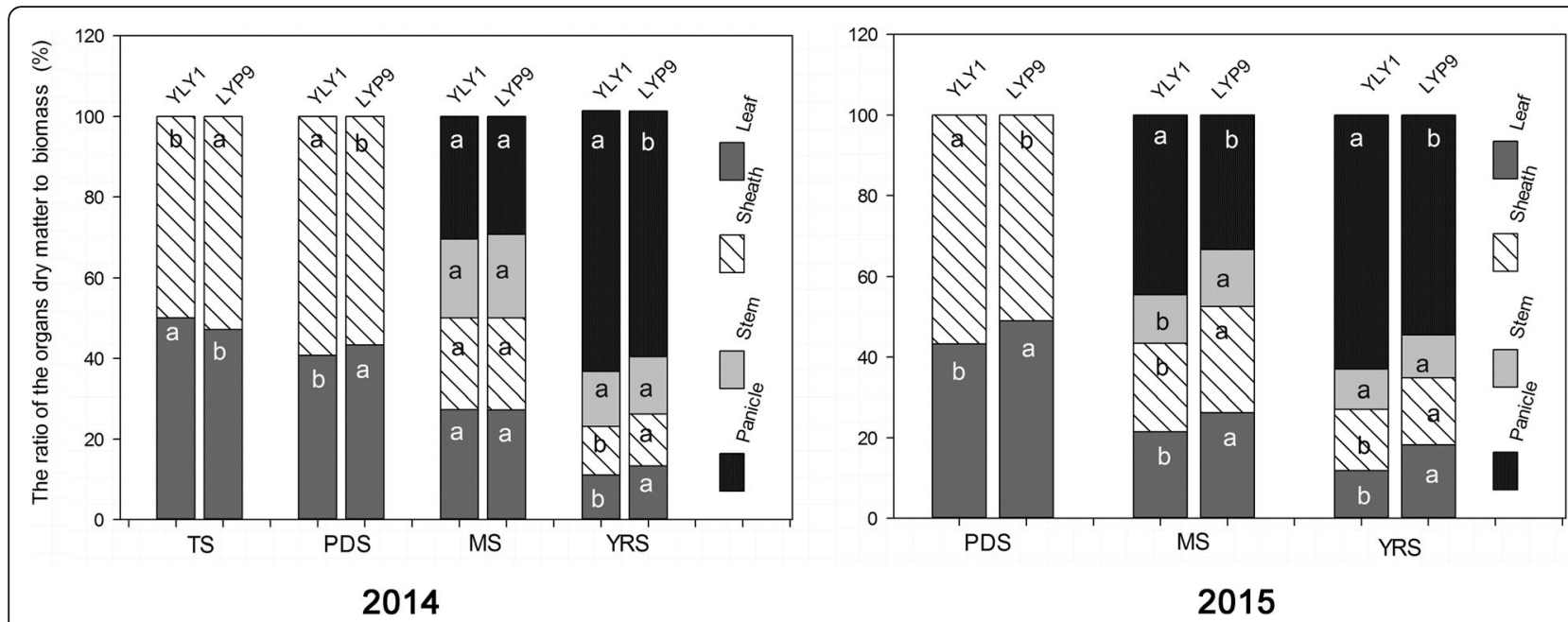

Fig. 7 The biomass composition at different developmental stages in 2014 and 2015. The ratios of biomass in four different tissues, including leaf, sheath, stem and panicle, to total biomass are shown in the figure. Data for four different stages are shown. See definitions of different stages in Fig. 4. The different letter means represent significance levels of $p=0.05$ level

Yongyou12\# is a representative indica-japonica hybrid rice cultivar, which reaches a yield of 13.5 tons per acre in 2012 (Chen et al. 2014). Features associated with the high yield of Yongyou12\# include a large area for the uppermost three leaves, a larger number of internodes, longer panicle-linked internode, shorter basal internodes with a large diameter, high stature, smaller basal leaf angle which results in a greater light penetration into the canopy. Similar to YLY900, Yongyou12\# shows a longer functional duration for photosynthetic leaves, has a large number of leaves per plant and has a high demand for nitrogen fertilizers at later developmental stages (Wei et al. 2016).

Apparently, features associated with the high yield in YLY1, YLY900 and Yongyou12\# differ dramatically. For example, compared to both YLY900 and Yongyou, YLY1 has a lower total area for the uppermost three leaves, greater total leaf area, and higher photosynthetic rate on an area basis. In terms of the canopy architecture, the height of YLY1 is greater than YLY900 but less than Yongyou12\# (China Rice Data Center: http://www.ricedata.cn/variety/varis/604222.htm). These differences between architectural and physiological features in YLY1, YLY900 and Yongyou12\# may be explored to further increase yield potential of these cultivars. Here systems models can be used to identify the most appropriate feature combinations to improve each one of these cultivars specifically, as has been demonstrated recently for Huanghuazhan and 9311 (Shi et al. 2019).

\section{Specific Architectural and Physiological Features of YLY1 which Can be Adopted in the Future High-Yield Rice Breeding Programs}

As discussed in the earlier session, the major mechanisms responsible for high yield potential of YLY1 include increased photosynthetic rates, decreased root: shoot ratio, increased capacity for stem and sheath non-structural carbohydrate storage, high capacity of mobilization, long functional duration of leaves, and finally more productive tillers. All these features are desired features for high yield formation in rice. In this section, we specifically emphasized two features for the high yield of YLY1, which gained relatively less attention in the breeding community so far. First, in terms of canopy architecture, YLY1 has a relatively smaller leaf area and smaller leaf angle in the top canopy layers compared to LYP9. Such architectural feature of YLY1 enables better light penetration into deeper canopy, which can contribute to the maintenance of photosynthetic properties at bottom layer leaves, better air flow in the canopy and hence higher disease resistance. The second feature that we emphasize here is the decreased root:shoot ratio and also increased root nitrogen uptake capacity in YLY1. Decreased biomass partitioning into root benefits canopy development and photosynthetic production, while increased root nitrogen uptake capacity can enable the root system to maintain sufficient capacity for nitrogen supply to support aboveground growth and photosynthesis.

\section{Material and Methods \\ Field Experiments}

Experiments were conducted at the experimental station of the China National Hybrid Rice R\&D Center, Changsha, China ( $\left.28^{\circ} 11^{\prime} 59^{\prime \prime} \mathrm{N}, 113^{\circ} 04^{\prime} 35^{\prime \prime} \mathrm{E}\right)$ from 2011 to 2016 . We used two cultivars of Indica hybrid rice (Oryza sativa L.), LYP9 (Pai64S/9311), super hybrid rice released in China in 1999 and YLY1 (Y58S/9311), a super hybrid rice cultivar 


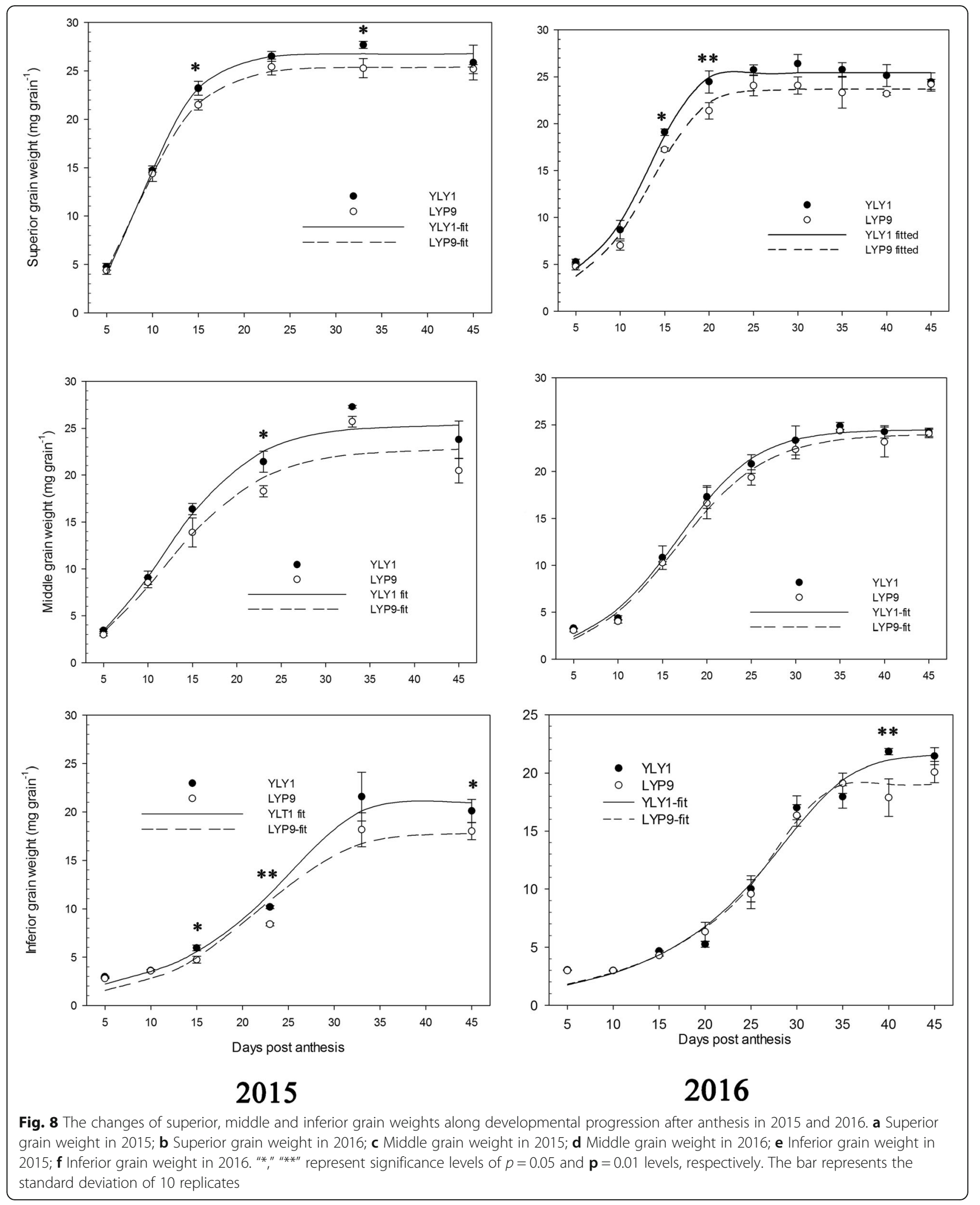




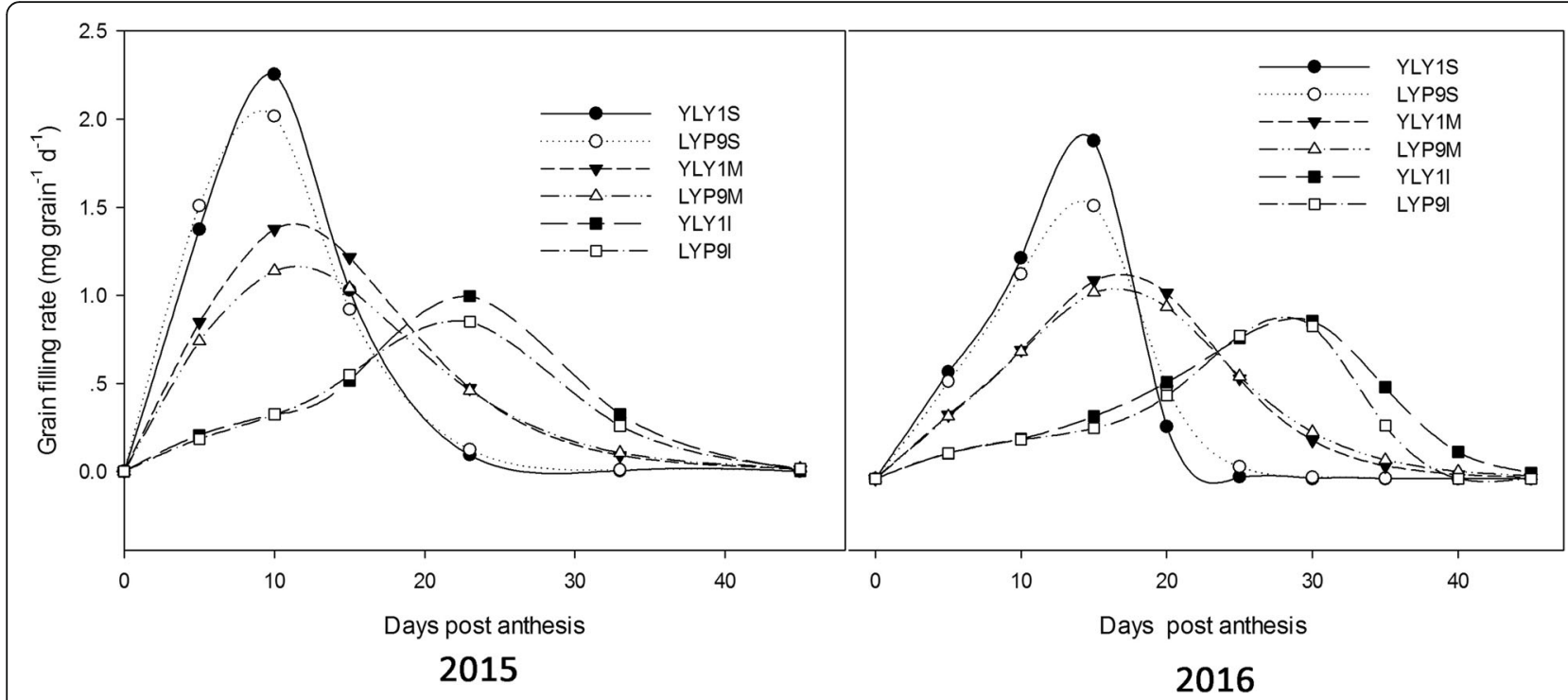

Fig. 9 The superior, middle and inferior grain filling rates after anthesis in 2015 (a) and 2016 (b). YLY1S represents superior grain of panicle in YLY1, YLY1 represents the middle grain in panicle of YLY1, YLY11 represents the inferior grain of panicle in YLY1. LYP9S represents superior grain of panicle in LYP9, LYP9 represents the middle grain in panicle of LYP9, LYP9I represents the inferior grain of panicle in LYP9. The bar represents the standard deviation of 10 replicates

released in China in 2006. Seeds were sown on seedbeds in the field after germination. There were 150 hills per plot and 3 plots were planted for each hybrid rice line. Seedlings were transplanted into the field at the 4th leaf stage, i.e. when the 4th leaf is completely expanded. One plant was sown into each hill with a planting density of 29.4 hills $\mathrm{m}^{-2}(0.20 \times 0.17 \mathrm{~m})$ in 2011,2012 , and 25 hills $\mathrm{m}^{-2}$ $(0.20 \times 020 \mathrm{~m})$ in 2013, 2014, 2015 and 2016. Fertilizer was supplied according to local standard agronomic practice for growing rice: $250 \mathrm{~kg} \mathrm{Nha}^{-1}, 150 \mathrm{~kg} \mathrm{P}_{2} \mathrm{O}_{5} \mathrm{ha}^{-1}$ and 250 $\mathrm{kg} \mathrm{K}_{2} \mathrm{O} \mathrm{ha}{ }^{-1}$. All of the potassium and phosphorus fertilizer, and $60 \%$ of the total nitrogen were applied before transplantation as basal fertilizer. The remaining 40\% N was applied as top dressing at the early panicle differentiation stage. Experiments follow a random block design.
YLY1 and LYP9 have similar developmental progressions. So, in this study, we applied the same nitrogen fertilizer quantity and also application scheme. The different nitrogen requirements between YLY1 and LYP9 will be studied separately.

\section{Measurement of Leaf Chlorophyll Contents}

The chlorophyll contents of leaves were measured with a SPAD-502(Minolta Camera Co. Ltd., Japan). We used the fully expanded leaves and 10 replicates among the three plots were used for the measurements at TS, PDS, MS and YRS in 2014 and 2015, then the SPAD vs actual chlorophyll content calibration was established for calculating actual chlorophyll content of two rice varieties, respectively.
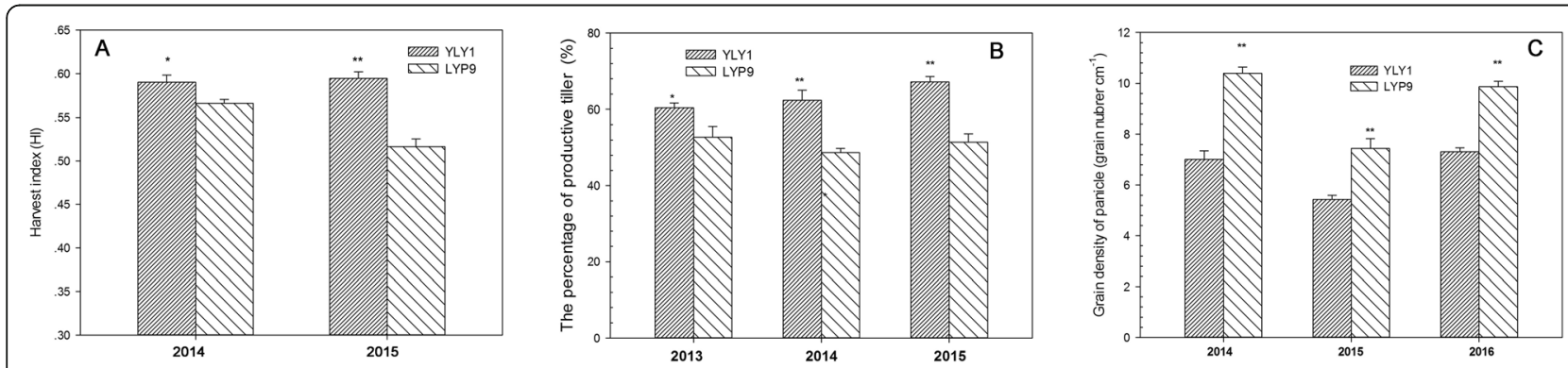

Fig. 10 The harvest indexes of YLY1 and LYP9 in 2014 and 2015 (a); the percentage of productive tillers in YLY1 and LYP9 in 2013, 2014, and 2015 (b); the grain density of panicle (c). ${ }^{\prime *}$," " "**" represent significance levels of $p=0.05$ and $p=0.01$ levels, respectively. The bar represents the standard deviation of 5 replicates 
Table 6 Yield components, plant height and panicle length for YLY1 and LYP9 from 2011 to 2016. $n=10$, "*," "***" represent significance levels of $p=0.05$ and $p=0.01$ levels

\begin{tabular}{|c|c|c|c|c|c|c|c|}
\hline Variety & Year & $\begin{array}{l}\text { Plant height } \\
(\mathrm{cm})\end{array}$ & $\begin{array}{l}\text { Panicle length } \\
(\mathrm{cm})\end{array}$ & Spikelets panicle $\mathrm{e}^{-1}$ & $\begin{array}{l}\text { 1000-grain } \\
\text { weight (g) }\end{array}$ & $\begin{array}{l}\text { Seed setting } \\
\text { rate(\%) }\end{array}$ & $\begin{array}{l}\text { Effective panicles } \\
\text { number per hill }\end{array}$ \\
\hline \multirow[t]{6}{*}{ YLY1 } & 2011 & $121.8 \pm 3.19$ & $28.5 \pm 1.12$ & $226.67 \pm 15.95$ & / & $92.24 \% \pm 1.23$ & / \\
\hline & 2012 & $121.0 \pm 2.34$ & $29.1 \pm 1.82$ & $217.0 \pm 26.9$ & / & $95.00 \% \pm 1.36$ & / \\
\hline & 2013 & $121.70 \pm 0.20$ & $28.00 \pm 0.45$ & $170.41 \pm 4.3$ & $26.13 \pm 0.38$ & $81.39 \pm 0.94 \%$ & $12.67 \pm 0.33$ \\
\hline & 2014 & $129.98 \pm 1.28$ & $25.51 \pm 0.58$ & $181.36 \pm 11.38$ & $27.73 \pm 0.28$ & $90.75 \pm 1.06 \%$ & $10.0 \pm 0.26$ \\
\hline & 2015 & $118.02 \pm 1.81$ & $26.31 \pm 0.35$ & $148.56 \pm 4.84$ & $27.24 \pm 0.47$ & $93.45 \pm 0.50 \%$ & $13.00 \pm 0.37$ \\
\hline & 2016 & $125.08 \pm 0.42$ & $28.56 \pm 0.34$ & $214.81 \pm 7.19$ & 27.3767 & $91.00 \pm 0.54 \%$ & $11.50 \pm 0.43$ \\
\hline \multirow[t]{9}{*}{ LYP9 } & 2011 & $110.6 \pm 1.15$ & $24.9 \pm 0.89$ & $242.00 \pm 36.00$ & / & $87.92 \% \pm 2.25$ & / \\
\hline & 2012 & $120.4 \pm 4.04$ & $25.3 \pm 1.02$ & $208.2 \pm 7.90$ & / & $91.41 \% \pm 2.08$ & / \\
\hline & 2013 & $116.60 \pm 1.43$ & $26.61 \pm 0.42$ & $177.62 \pm 5.02$ & $26.01 \pm 0.31$ & $82.47 \pm 1.06 \%$ & $10.29 \pm 0.18$ \\
\hline & 2014 & $129.67 \pm 1.30$ & $22.34 \pm 0.53$ & $233.82 \pm 6.43$ & $27.58 \pm 0.33$ & $90.50 \pm 1.78 \%$ & $8.4 \pm 0.25$ \\
\hline & 2015 & $120.50 \pm 1.56$ & $24.82 \pm 0.47$ & $184.26 \pm 9.68$ & $26.58 \pm 0.13$ & $89.19 \pm 0.43 \%$ & $9.50 \pm 0.34$ \\
\hline & 2016 & $121.94 \pm 1.49$ & $26.51 \pm 0.29$ & $263.51 \pm 6.37$ & 26.5587 & $87.78 \pm 0.47 \%$ & $9.40 \pm 0.40$ \\
\hline & Cultivar(A) & * & $* *$ & $* *$ & NS & $* *$ & $* *$ \\
\hline & Year (B) & $* *$ & $* *$ & $* *$ & $* *$ & * & $* *$ \\
\hline & $A \times B$ & NS & NS & $* *$ & NS & $* *$ & $* *$ \\
\hline
\end{tabular}

\section{Measurement of Net Photosynthetic $\mathrm{CO}_{2}$ Uptake Rate and Dark Respiration Rate}

Net photosynthetic rate $\left(\mathrm{P}_{\mathrm{n}}\right)$ was measured with a portable photosynthesis system LI-6400XT (LI-COR, Lincoln, NE, USA). The photosynthetic photon flux density (PPFD) used for measurement of $\mathrm{P}_{\mathrm{n}}$ were $1000 \mu \mathrm{mol}$ $\mathrm{m}^{-2} \mathrm{~s}^{-1}$ at TS, PDS, HFS, MS and DS. The PPFD for measuring $A_{\text {sat }}$ (maximum light saturated rate of leaf photosynthesis) were $1600 \mu \mathrm{mol} \mathrm{m}^{-2} \mathrm{~s}^{-1}$ at TS, EPDS, LPDS, MS and DS. The $\mathrm{P}_{\mathrm{n}}$ and $\mathrm{A}_{\text {sat }}$ were recorded after leaves were acclimated in a leaf chamber for about $5 \mathrm{~min}$. The leaf temperature during the measurement was maintained at $25 \sim 30{ }^{\circ} \mathrm{C}$. We alternated the cultivars during the measurements to avoid having leaves from one cultivar experience constant high or low temperature. The ambient $\mathrm{CO}_{2}$ concentration was about $380 \mathrm{ppm}$ from atmosphere (in 2011) and controlled to be around 380 ppm in 2012, 2013, 2014, 2015, and 2016. The measurements were conducted between 9:30 to 12:00 on sunny days for the uppermost fully expanded leaves. Dark respiration of flag leaves in YLY1 and LYP9 were measured by Li-6800 at the MS, with 10 replicates among the three plots between 20:00 to 21:30 at night in 2016 .

\section{Net Photosynthesis Rate of Leaves in Different Positions on the Main Panicle Stem}

To characterize differences of photosynthetic activity in leaves other than the uppermost leaf, we measured $\mathrm{P}_{\mathrm{n}}$ of each leaf on the main panicle stem at the milk (6 green leaves) and dough (4 green leaves) stages in 2013. Measurements were made between 9:30 and 12: 00 on sunny days.

\section{Light Response Curves}

Net photosynthetic $\mathrm{CO}_{2}$ assimilation rate $\left(\mathrm{P}_{\mathrm{n}}\right)$ was measured at different light intensities from high light to low light levels, i.e. 2000, 1800, 1500, 1200, 1000, $800,600,400,200,150,100,50,20$ and $0 \mu \mathrm{mol} \mathrm{m}^{-2}$

Table 7 The grain length, width and the ratio of length/width were measured by SC-Grice grain appearance quality image analysis system (Hangzhou WSeen Detection Technology Co., Ltd., China) for CV. YLY1 and LYP9 in 2015 and 2016

\begin{tabular}{|c|c|c|c|c|c|c|c|c|}
\hline \multicolumn{5}{|l|}{2015} & \multicolumn{4}{|l|}{2016} \\
\hline & $\begin{array}{l}\text { YLY1 } \\
(\text { mean } \pm S E)\end{array}$ & LYP9 (mean \pm SE) & Difference & $p$ & $\begin{array}{l}\text { YLY1 } \\
(\text { mean } \pm \text { SE) }\end{array}$ & LYP9 (mean \pm SE) & Difference & $p$ \\
\hline Grain length & $9.32 \pm 0.17$ & $8.86 \pm 0.09$ & $5.19 \%$ & $<0.01$ & $9.50 \pm 0.09$ & $9.06 \pm 0.07$ & $4.86 \%$ & $<0.01$ \\
\hline Grain width & $2.63 \pm 0.02$ & $2.64 \pm 0.02$ & $-0.38 \%$ & $<0.01$ & $2.56 \pm 0.02$ & $2.51 \pm 0.04$ & $1.99 \%$ & $<0.01$ \\
\hline Ratio of grain length/width & $3.57 \pm 0.02$ & $3.38 \pm 0.03$ & $5.62 \%$ & 0.22 & $3.74 \pm 0.02$ & $3.63 \pm 0.02$ & $3.03 \%$ & 0.12 \\
\hline
\end{tabular}


Table 8 Theoretical grain yield for 2013 to2016 Experiments were conducted in three plots. Grain yields from 50 hills were measured and used to estimate the theoretical yield. $n=3$, the grain yield of 2011, 2012 according the grain weight of 10 hills, "**" " "*** represent significance levels of ${ }^{\mathrm{P}}=0.05$ and $^{\mathrm{P}}=0.01$ levels

\begin{tabular}{|c|c|c|c|c|c|c|}
\hline & 2011 & 2012 & 2013 & 2014 & 2015 & 2016 \\
\hline$\overline{Y L Y 1}$ & $\begin{array}{l}9.84 \pm \\
0.782\end{array}$ & $\begin{array}{l}11.62 \pm \\
2.999\end{array}$ & $\begin{array}{l}9.82 \pm \\
0.98\end{array}$ & $\begin{array}{l}10.20 \pm \\
0.113\end{array}$ & I & $\begin{array}{l}11.69 \pm \\
0.54\end{array}$ \\
\hline LYP9 & $\begin{array}{l}9.36 \pm \\
1.051\end{array}$ & $\begin{array}{l}10.76 \pm \\
1.003\end{array}$ & $\begin{array}{l}9.09 \pm \\
1.00\end{array}$ & $\begin{array}{l}9.64 \pm \\
0.146\end{array}$ & / & $\begin{array}{l}11.08 \pm \\
0.85\end{array}$ \\
\hline Difference & $5.13 \%$ & $7.99 \%$ & $8.03 \%$ & $5.81 \%$ & / & $5.51 \%$ \\
\hline$p$ & 0.434379 & 0.522719 & 0.39103 & $<0.05$ & / & $<0.05$ \\
\hline $\begin{array}{l}\text { Cultivar(A) } \\
\text { Year (B) } \\
A \times B\end{array}$ & $\begin{array}{l}{ }^{* *} \\
* * \\
\text { NS }\end{array}$ & & & & & \\
\hline
\end{tabular}

$\mathrm{s}^{-1}$. The $\mathrm{CO}_{2}$ concentration was maintained at 380 $\mathrm{ppm}$. The light response curve was fitted with a rectangular hyperbola (Long et al. 1994) using SPSS13.0 (SPSS Inc., Chicago, USA).

$$
P_{n}=\frac{a I+P_{n \max }-\sqrt{\left(a I+P_{n \max }\right)^{2}-4 \theta I P_{n \text { max }}}}{2 \theta}-R_{d}
$$

Where $P_{n}$ is the net photosynthetic $\mathrm{CO}_{2}$ uptake rate, $\alpha$ is apparent quantum yield (AQY), $I$ is photosynthetic photo flux density (PPFD), $\theta$ is curve convexity, $P_{\text {nmax }}$ is the maximal $P_{n}, R_{d}$ is the dark respiration rate.

\section{Responses of $\mathrm{P}_{\mathrm{n}}$ to $\mathrm{CO}_{2}$ Concentration}

The responses of $\mathrm{P}_{\mathrm{n}}$ under different $\mathrm{CO}_{2}$ concentrations (A/Ci curve) were measured under a saturated PPFD of $1600 \mu \mathrm{mol} \mathrm{m}{ }^{-2} \mathrm{~s}^{-1}$. The $\mathrm{CO}_{2}$ concentrations used first decreased from 425 to $50 \mathrm{ppm}$, i.e. $425,350,250,150,100$, 50 , and then set to $425 \mathrm{ppm}$ for at least $15 \mathrm{~min}$, and then increased to $1800 \mathrm{ppm}$, i.e. 500, 700, 900, 1100, 1300, 1500 and $1800 \mathrm{ppm}$. To fit the maximal rate of carboxylation at RuBP and $\mathrm{CO}_{2}$ saturation $\left(\mathrm{V}_{\mathrm{cmax}}\right)$ and light saturated rate of electron transfer $\left(\mathrm{J}_{\max }\right)$ in the Farquhar model (Farquhar et al. 1980) (Eq. 2-4), least squared method in Gnumeric software was applied by setting $\mathrm{K}_{\mathrm{c}}$ to 404 mbar, $\mathrm{K}_{\mathrm{o}}$ to $278 \mathrm{mbar}, \mathrm{O}$ to $210 \mathrm{mbar}$ and " to $45 \mathrm{ppm}$. In the Farquhar model, $\mathrm{W}_{\mathrm{c}}$ is RuBISCO limited photosynthesis rate and $W_{j}$ is $R u B P$ regeneration limited photosynthesis rate. $R_{d}$ is the dark respiration rate of leaf. $C_{i}$ is intercellular $\mathrm{CO}_{2}$ concentration and $\mathrm{K}_{\mathrm{c}}$ is RuBISCO Michaelis menten constant for $\mathrm{CO}_{2}$ and $\mathrm{K}_{\mathrm{o}}$ is RuBISCO Michaelis menton constant for $\mathrm{O}_{2}$. "is the $\mathrm{CO}_{2}$ compensation point in the absence of dark respiration.

$$
P_{n}=\min \left(W_{c}, W_{j}\right)-R_{d}
$$

$$
\begin{aligned}
& W_{c}=V_{c \max } \frac{C i}{C i+k_{c}\left(1+O / k_{o}\right)} \\
& W_{j}=\frac{J_{\max } \cdot C i}{4 \cdot C i+8 \cdot \Gamma^{*}}
\end{aligned}
$$

\section{Leaf Area}

Leaf areas of the flag leaf, and the basipetal 2rd, 3rd, and 4th leaves of main stems were measured at the milk stage using a handheld laser leaf area meter (Ci-203, CID, Inc., Vancouver, WA, USA). We also measured lag leaf, and the basipetal 2rd, 3rd leaves from 10 stems among the three plots at TS, PDS, MS and YRS in 2013, 2014 and 2015.

\section{Canopy Photosynthesis}

Canopy photosynthesis was measured using a specialized system named as canopy photosynthesis and transpiration system (CAPTS) (MilletHill Biotech, Shanghai, China) contain 10 chambers with a controller. CAPTS is an automatic closed-chamber system and a detailed description of the performance and protocol to use CAPT $\mathrm{S}$ was provided in (Song et al. 2016; Song and Zhu 2018). CAPTS was used in previous study (T.-G. Chang et al. 2019) for measuring rice canopy photosynthesis. The size of each chamber is $\left(1^{*} 1^{*} 1.5\right) \mathrm{m}^{3}\left(\mathrm{~L}^{*} \mathrm{~W}^{*} \mathrm{H}\right)$, cover a rice canopy with a ground area of $1 \mathrm{~m}^{2}$. The top of each chamber can be automatically open and close by the controller. The top covers of the chambers were first closed and then open in a consecutive cyclic way. The time duration to open or close the top of the chamber can also be set on the controller. Here, we select $45 \mathrm{~s}$ duration to close a chamber for one measurement and the chamber was kept open for $495 \mathrm{~s}$ when doing measurement on the other chambers. Once the chamber is in closed form, the gas in the chamber was pumped out by the controller for measuring $\mathrm{CO}_{2}$ concentration $\left[\mathrm{CO}_{2}\right]$ (logging $\left[\mathrm{CO}_{2}\right]$ for each second), and then the gas returned back to the chamber. The slope of $\left[\mathrm{CO}_{2}\right]$ change against time is calculated with a data analyzing software CAPTS Suite that follow linear regression method (Song et al. 2016; Song and Zhu 2018). The CAPTS Suite is a specialized software for analyzing raw data of CAPTS and convert into canopy gas exchange rate.

\section{The Weight of Superior, Middle and Inferior Grains and Grain Filling Rate}

A total of 200 panicles that headed on the same day were chosen and tagged. The flowering date and the position of each spikelet on the tagged panicles were recorded in 2015 and 2016. Ten tagged panicles from each plot were sampled at a 5-day interval from anthesis to 
maturity. The middle grains determined as those locating at the middle of a panicle, the superior and inferior grains were identified following (Zhu et al. 1988). The progression of grain filling was fitted using a modified Richards growth equation (Richards 1959).

\section{Agronomic Parameters}

The diameter of stem was measured with a vernier caliper (instrument precision, $0.01 \mathrm{~mm}$ ) at YRS in 2014 and 2015. The methods for measuring stem diameter follow (Chang et al. 2016) with five replicates for each leaf and stem. The height of rice and length of stem were measured by a ruler with $1 \mathrm{~mm}$ scale.

Rice plants from ten hills (for year 2011, 2012, 2014, 2015) were harvested at TS, PDS, MS and YRS for the measurements of agronomic parameters. The above ground biomass was measured after plants were heated at $70^{\circ} \mathrm{C}$ from ten hills for the year 2011 and 2012, the leaf, sheath, stem and panicle were weighted after departing from the plants, the ratio of organs dry matter $=$ the organ (leaf, sheath, stem, panicle) weight / the above ground biomass $\times 100 \%$; the productive tiller percentage $=$ the productive panicle number per hill at yellow ripe stage / the max tiller number at tilling stage $x$ $100 \%$. The grain yield was calculated based on measurements from 50 hills each plot for the year 2013, 2014, 2015 and 2016, with three plots as replicates. The harvest index was measured with a ratio of weight of grain to above ground biomass with ten hill replicates. The grain length and width were evaluated by SC-Grice grain appearance quality image analysis system developed by Hangzhou WSeen Detection Technology Co., Ltd., China (Yin et al. 2015).

\section{Statistical Analysis}

Analysis of variance (ANOVA) of $\mathrm{P}_{\mathrm{n}}$ data was conducted and significance of mean differences was determined using the LSD method in DPS7.05 (Zhejiang University, China).

\section{Conclusion}

The high yield of YLY1 is attributed to a number of architectural and physiological parameters, including high canopy photosynthesis, higher photosynthate reserve in leaf sheath before grain filling, more effective photosynthate allocation, especially at the grain filling stage and higher proportion of productive tillers. Some of these identified features still can be used as generic features in modern high-yield rice breeding. Hence molecular basis underlying these features should be identified to facilitate high-yield rice breeding.

\section{Supplementary information}

Supplementary information accompanies this paper at https://doi.org/10. 1186/s12284-020-00419-y.

Additional file 1: Table S1. The time for the appearance of different developmental stages in the rice during 2011 to 2016.

Additional file 2: Figure S1. The planting areas of top five hybrid rice cultivars in China.

Additional file 3: Figure S2. The dark respiration rates of flag leaves in YLY1 and LYP9 at the milk stage.

Additional file 4: Figure S3. The ratio of belowground biomass to the aboveground biomass for YLY1 and LYP9 measured in 2016.

\section{Abbreviations}

YLY1: Y-Liang-You 1"; LYP9: Liang-You-Pei-Jiu; $P_{n}$ : Net photosynthesis rate; $\mathrm{R}_{\mathrm{d}}$ : Dark respiration rate; $\mathrm{AQY}$ : Apparent quantum yield; Ca: Ambient $\mathrm{CO}_{2}$ concentration; $\mathrm{Ci}$ : Intercellular $\mathrm{CO}_{2}$ concentration; PPFD: Photosynthetic photo flux density; TS: Tillering stage; PDS: Panicle differentiation stage; EPDS: Early panicle differentiation stage; LPDS: Late panicle differentiation stage; HFS: Heading and flowering stage; MS: Milk stage of grain filling; EMS: Early milk stage of grain filling; LMS: Late milk stage of grain filling; DS: Dough stage of grain filling; YRS: Yellow ripe stage; $A_{c}$ : The integrated rate of photosynthetic $\mathrm{CO}_{2}$ assimilation of the canopy; $\mathrm{A}_{\text {sat }}: \mathrm{CO}_{2}$ assimilation at light saturation condition.

\section{Acknowledgements}

We are grateful to the anonymous reviewers for their constructive comments on revision of the manuscript.

\section{Authors' contributions}

SC, X-GZ and QD conceived and designed the experiments. SC, TC, QS, YL, XC performed the experiments. SC, JW and QS analyzed the data. SC, X-GZ and QD wrote the manuscript. The authors read and approved the final manuscript

\section{Funding}

This research was financially supported by the National key Research and Development Program of China (Grant No.2017YFD0301502), Project supported by National Natural Science Foundation of China (Grant No. 31871704), Hunan Provincial Natural Science Foundation (CN) (Grant No.2018JJ2286), and the project of Hunan hybrid rice research center (Grant No. YB201910), Chinese Academy of Sciences strategic leading project (XDA08020301).

\section{Availability of data and materials}

All data generated or analyzed during this study are included in this published article and its supplementary information files.

Ethics approval and consent to participate

Not applicable.

Consent for publication

Not applicable.

\section{Competing interests}

The authors declare that they have no competing interests.

\section{Author details}

'State Key Laboratory of Hybrid Rice, Hunan Hybrid Rice Research Center (HHRRC), Changsha 410125, China. ${ }^{2}$ National Key Laboratory of Plant Molecular Genetics, CAS Center of Excellence for Molecular Plant Sciences, Shanghai Institute of Plant Physiology and Ecology, CAS, Shanghai 200032, China. ${ }^{3}$ BioRice (Hunan) Co Ltd., Changsha 410100, China. 
Received: 22 January 2020 Accepted: 10 August 2020

Published online: 26 August 2020

\section{References}

Chang S, Chang T, Song Q, Zhu X, Deng Q (2016) Photosynthetic and agronomic traits of an elite hybrid rice Y-Liang-you 900 with a record-high yield. Field Crop Res 187:49-57

Chang T, Zhao H, Wang N, Song Q, Xiao Y, Qu M, Zhu X (2019) A threedimensional canopy photosynthesis model in rice with a complete description of the canopy architecture, leaf physiology, and mechanical properties. J Exp Bot 70(9):2479-2490

Chang T, Zhu X (2017) Source - sink interaction: a century old concept under the light of modern molecular systems biology. J Exp Bot 68(16):4417-4431

Chen Y, Mao G, Wang J (2014) Super high-yielding cultivation techniques of super hybrid Rice Yongyou 12. China rice 20(3):58-59

Cheng S, Cao L, Zhuang J, Chen S, Zhan X, Fan Y, Zhu D, Min S (2007) Super hybrid rice breeding in China: achievements and prospects. J Integr Plant Biol 49(6):805-810

Cheng S, Liao X, Min S (1998) China's "super"rice research: background, goals and issues. China Rice 1:3-5

Donald C (1968) The breeding of crop ideotypes. Euphytica 17(3):385-403

Evans J (1989) Partitioning of nitrogen between and within leaves grown under different irradiances. Aust J Plant Physiol 16(6):533-548

Farquhar G, Caemmerer V , Berry J (1980) A biochemical model of photosynthetic $\mathrm{CO}_{2}$ assimilation in leaves of $\mathrm{C} 3$ species. Planta 149(1):78-90

Huang M, Zou Y, Jiang P, Xia B, Xiao A (2012) Performance of super hybrid rice cultivars grown under no-tillage and direct seeding. Sci Agric 69(2):103-107

Li C (2013) Studies on morphological features and its regularities in super hybrid rice breeding. (Master), Central South University, Changsha

Li X, Jiao D (2002) Photosynthetic characteristics of super hybrid rice "Liangyoupeijiu". Jiangsu J Agric Sci 18(1):9-13

Ling Q, Gong J, Zhu Q (1982) Effects of leaves at different node-position on yield formation. J Yangzhou Univ (Agriculture and Life Sciences Edition) 3(2):9-26

Long S, Humphries S, Falkowski P (1994) Photoinhibition of photosynthesis in nature. Annu Rev Plant Biol 45(1):633-662

Lv C, Li X, Chen G (2017) Photosynthetic characteristics and its physiological basis of super high-yielding hybrid rice liangyoupeijiu. Sci Agric Sin 50:4055-4070

Ort D, Zhu X, Melis A (2011) Optimizing antenna size to maximize photosynthetic efficiency. Plant Physiol 155(1):79-85

Richards F (1959) A flexible growth function for empirical use. J Exp Bot 10(2): 290-301

Shi Z, Chang T, Chen G, Song Q, Zhu X (2019) Dissection of mechanisms for high yield in two elite rice cultivars. Field Crop Res 241:107563

Song Q, Wang Y, Qu M, Ort D, Zhu X (2017) The impact of modifying photosystem antenna size on canopy photosynthetic efficiency — development of a new canopy photosynthesis model scaling from metabolism to canopy level processes. Plant Cell Environ 40(12):2946-2957

Song Q, Xiao H, Xiao X, Zhu X (2016) A new canopy photosynthesis and transpiration measurement system (CAPTS) for canopy gas exchange research. Agric For Meteorol 217:101-107

Song Q, Zhu XG. (2018) Measuring Canopy Gas Exchange Using CAnopy Photosynthesis and Transpiration Systems (CAPTS). In: Covshoff S. (eds) Photosynthesis. Methods in Molecular Biology, vol 1770. Humana Press, New York, NY. https://doi.org/10.1007/978-1-4939-7786-4_4

Wang Z (2011) Comparative studies of super hybrid rice ratoon material transport disciplines. (Master) Hunan Agricultural University, Changsha

Wei H, Meng T, Chao L, Zhang H, Guo B (2016) Dynamic model and its characteristics analysis for dry matter production after heading of Indica/ japonica hybrid Rice of Yongyou series. Acta Agron Sin 42(2):265-277

Xia S, Zhang Q, Yang J (2011) Identification of S5-n gene and subspecies classification of indica and japonica in rice male sterile line. Jiangsu J Agric Sci 27(4):698-703

Xue Y, Chong K, Han B, Gui J, Wang T, Fu X, Cheng Z (2015) New chapter of designer breeding in China: update on strategic program of molecular modulebased designer breeding systems. Buttletin Chin Acad Sci 30:393-402

Yi Z (2016) Study on yield formation characteristics of different super hybrid rice varieties. (Master), Jiangxi Agricultal University, Nanchang

Yin C, Hi L, Li S, Xu L, Zhao Z, Wang J (2015) Genetic dissection on rice grain shape by the two-dimensional image analysis in one japonicax indica population consisting of recombinant inbred lines. Theor Appl Genet 128(10):1969-1986
Yuan $L$ (2000) Breeding of super hybrid rice. Paper presented at the international Rice research conference, Los Baños

Yuan L, Yang Z, Yang J (1994) Hybrid rice research in China hybrid rice technology: new developments and future prospects. Selected papers from the international rice research conference, Manila, pp 143-148

Zhu Q, Cao X, Luo Y (1988) Growth analysis in the process of grain filling in rice. Acta Agron Sin 14:182-193

Zou J (2003) Breeding of two-line hybrid rice variety'Liangyoupeijiu'and preliminary studies on its cultivation characters. Sci Agric 36(8):869-872

Zou J, Yao K, Lu C (2003) Study on individual plant type character of. Liangyoupeijiu rice Acta Agronomica Sinica 29(5):652-657

\section{Publisher's Note}

Springer Nature remains neutral with regard to jurisdictional claims in published maps and institutional affiliations.

\section{Submit your manuscript to a SpringerOpen ${ }^{\circ}$ journal and benefit from:}

- Convenient online submission

- Rigorous peer review

- Open access: articles freely available online

High visibility within the field

- Retaining the copyright to your article

Submit your next manuscript at $\boldsymbol{\nabla}$ springeropen.com 